\section{1) Ulosiversidad de}

Escuela de Gobierno

Alberto Lleras Camargo

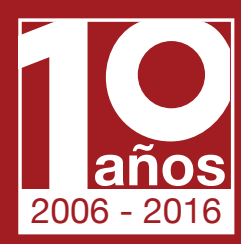

$2006-2016$

\title{
No. 37
}

Diciembre 2016

ISSN $2215-7816$

\section{Documentos de Trabajo}

Escuela de Gobierno Alberto Lleras Camargo

Caracterización de la educación media en Colombia

Expectativas y percepciones de padres de familia y docentes sobre las funciones sociales y educativas de la educación media

Eddier Martínez y Jorge Celis 
Serie Documentos de Trabajo 2016

Edición No. 37

ISSN $2215-7816$

Edición electrónica

Diciembre de 2016 C 2016 Universidad de los Andes - Escuela de Gobierno Alberto Lleras Camargo

Carrera 1 No. 19 -27, Bloque AU | Bogotá, D.C., Colombia

Teléfonos: 3394949 / 99 Ext. 2073

escueladegobierno@uniandes.edu.co

http://egob.uniandes.edu.co

\section{Ministerio de Educación Nacional}

Ministra de Educación Nacional

Yaneth Giha Tovar

Viceministro de Educación Preescolar, Básica y Educación Media

Víctor Javier Saavedra Mercado

Directora de Calidad de Educación Preescolar, Básica y Educación Media

Paola Andrea Trujillo Pulido

Asesora Proyecto de Modernización de la Educación Media

Juliana Suárez Cortés

Coordinación técnica del convenio Ministerio de Educación Nacional y la Universidad de los Andes

Santiago Varela Londoño

Universidad de los Andes

Director Escuela de Gobierno Alberto Lleras Camargo

Carlos Caballero Argáez

Coordinador del Convenio 834 de 2015

Mauricio Duque

Coordinador del proyecto de Caracterización de la educación media, Convenio 834 de 2015

Darío Maldonado

Coordinadores del Convenio 1109 de 2016

Sandra García Jaramillo y Darío Maldonado

Autores

Eddier Martínez y Jorge Celis

Jefe de Mercadeo y Comunicaciones Escuela de Gobierno Alberto Lleras Camargo

Camilo Andrés Torres Gutiérrez

Gestora Editorial Escuela de Gobierno Alberto Lleras Camargo

Angélica María Cantor Ortiz

Gestor de Comunicaciones Escuela de Gobierno Alberto Lleras Camargo

Luis Carlos López Fuentes

El contenido de la presente publicación se encuentra protegido por las normas internacionales y nacionales vigentes sobre propiedad intelectual, por tanto su utilización, reproducción, comunicación pública, transformación, distribución, alquiler, préstamo público e importación, total o parcial, en todo o en parte, en formato impreso, digital o en cualquier formato conocido o por conocer, se encuentran prohibidos, y solo serán lícitos en la medida en que cuente con la autorización previa y expresa por escrito del autor o titular. Las limitaciones y excepciones al Derecho de Autor solo serán aplicables en la medida en se den dentro de los denominados Usos Honrados (Fair Use); estén previa y expresamente establecidas; no causen un grave e injustificado perjuicio a los intereses legítimos del autor o titular; y no atenten contra la normal explotación de la obra. 


\title{
Expectativas y percepciones de padres de familia y docentes sobre las funciones sociales y educativas de la educación media*
}

\author{
Eddier Martínez ${ }^{+}$y Jorge Celis ${ }^{\#}$
}

\begin{abstract}
Resumen
Este documento presenta los resultados de analizar las expectativas y percepciones que padres de familia y docentes tienen sobre las funciones sociales y educativas de la educación media. Para tal fin, se conformaron 32 grupos focales en los departamentos de Sucre y Antioquia en el 2015. Padres de familia y docentes mencionan que la educación media debe preparar a los estudiantes para ingresar al mercado de trabajo, aunque también afirman que los debe formar para el ingreso a la educación superior. De ahí la importancia de que exista un balance entre las competencias generales y las laborales. Cuestionan también la duración de dos años de la educación media. Consideran que la duración debería ser de tres años, pues dos años no son suficientes para que los estudiantes puedan tomar decisiones sobre su vida adulta. Algunos participantes en los grupos focales abogan por que la educación media esté más articulada con la educación superior mediante cursos que puedan ser ofrecidos por instituciones de educación superior y, posteriormente, reconocidos como parte del programa que cursen los estudiantes una vez ingresen a la educación superior.
\end{abstract}

\begin{abstract}
This paper shows the results derived from the analysis done over parents' and teachers' expectations and perceptions on the social and educative functions of upper-secondary education. To this end, 32 focus groups were done in Sucre and Antioquia Departments in 2015. Parents and teachers say that upper-secondary education has the function of preparing students for the labor market, albeit it provides students with skills to access higher education. Consequentially, it is important that there exists a balance between generic and labor-oriented market skills. Parents and teachers consider that the length of upper-secondary education should be three years, since two years are not enough in order students to make decisions over their life as adults. Some participants in the focus groups mention that upper-secondary education should be more articulated with higher education by means of courses offered by higher education institutions. These courses could be recognized as part of bachelor program when students finally access higher education.

\footnotetext{
* Este proyecto fue parte del Convenio de asociación 834 de 2015 entre el Ministerio de Educación, la Universidad de los Andes, la Universidad Externado y la Universidad Nacional de Colombia. El líder del convenio fue Mauricio Duque y Darío Maldonado fue el coordinador de todo el proyecto Caracterización de la Educación Media. María Paula Rojas estuvo a cargo de la administración del proyecto. En el trabajo de campo para este trabajo contamos con el apoyo de FINAC S.A., Diversidad Rural y la asistencia de Glenda Palacios. El proyecto contó con el valioso apoyo de diversos funcionarios del MEN que ayudaron a definir las preguntas de investigación y revisaron los resultados de proyecto en varias etapas. En particular agradecemos a Laura Barragán, Ana Bolena Escobar, Alejandra López, Nataly Obando, Manuel Rivera, Víctor Saavedra, Adolfo Sánchez, Juliana Suárez, Paola Trujillo y Santiago Varela.

+ Antropólogo, magíster en Sociología, Universidad Nacional de Colombia, investigador independiente. eamartineza@unal.edu.co.

\# Grupo de investigación de Estudios de Educación Media y Superior, Universidad Nacional de Colombia. jecelisg@unal.edu.co.
} 


\section{Tabla de contenido}

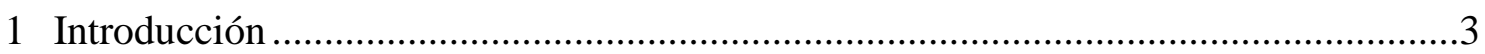

2 Aspectos metodológicos ...................................................................................

2.1 Criterios para la selección de los establecimientos educativos ...............................5

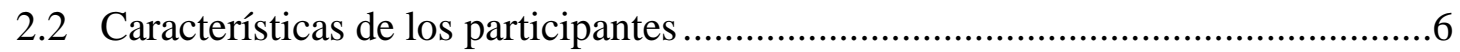

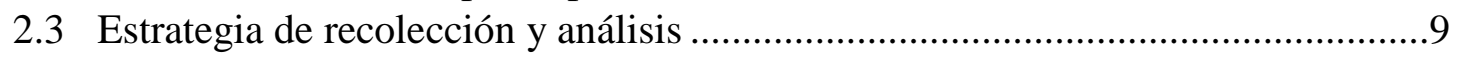

3 Funciones sociales y educativas de la educación media.............................................12

3.1 Preparación para el ingreso al mercado de trabajo ................................................13

3.2 Preparación para el ingreso a la educación superior ...............................................17

3.3 Formación integral en valores y descubrimiento de aptitudes...............................24

3.3.1 Exploración y descubrimiento de intereses ..................................................25

3.3.2 Formación para el ejercicio activo de la ciudadanía.........................................26

3.3.3 Ofrecer oportunidades para el desarrollo de las capacidades de los

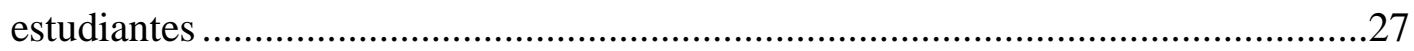

4 Organización de la educación media .......................................................................28

4.1 Duración de la educación media........................................................................29

4.2 Contenidos curriculares de la educación media.......................................................31

4.2.1 Contextualización del currículo de la educación media de acuerdo con las características regionales particulares .......................................................................

4.2.2 Mayor énfasis en la práctica que en los contenidos teóricos, concentrándose en aprendizajes útiles para la vida laboral...............................................................32

4.2.3 Intensidad horaria destinada a las asignaturas de acuerdo con las

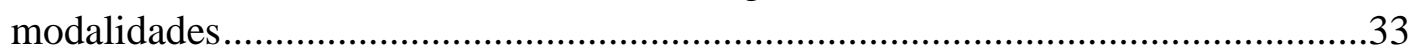

4.3 Edad de egreso de los estudiantes......................................................................

5 Las relaciones que se tejen alrededor de la educación media.......................................36

5.1 Relación de las familias con los establecimientos educativos ................................37

5.2 Relaciones del establecimiento educativo con el sector productivo......................42

5.3 Relaciones del establecimiento educativo con la educación superior ...................44

5.3.1 Relevancia y participación del SENA en el establecimiento educativo ..........44

5.3.2 Universidades con proyectos o practicantes dentro del establecimiento

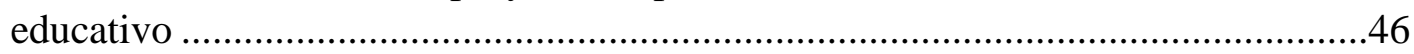

5.3.3 Convenios para articular la educación media con la educación superior .....46

5.3.4 Ferias educativas y espacios de promoción de las universidades a los estudiantes de grado undécimo

5.3.5 Becas ofrecidas por universidades a egresados de algunas instituciones

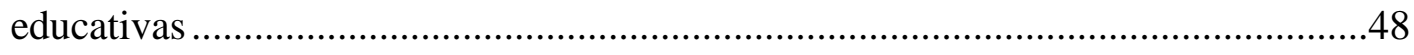

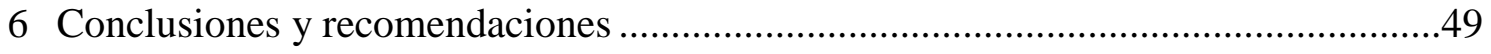

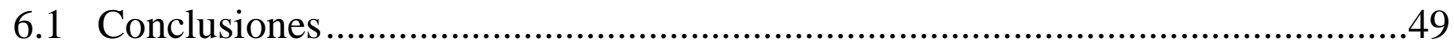

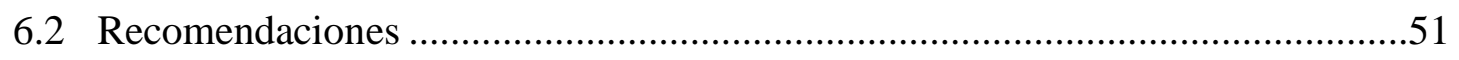

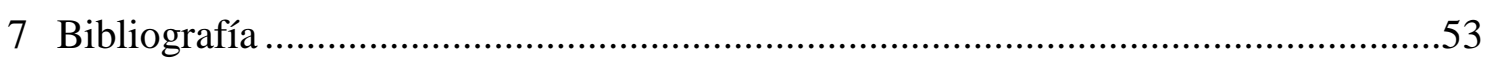




\section{Introducción}

Este documento tiene como propósito analizar las expectativas y percepciones que padres de familia y docentes pertenecientes a 16 establecimientos educativos oficiales tienen sobre 1) las funciones sociales y educativas de la educación media (ingreso a la educación superior y mercado de trabajo, exploración de intereses, ciudadanía, desarrollo de capacidades), 2) la organización de la educación media (duración teórica, contenidos curriculares, edad de egreso de los estudiantes) y 3) las relaciones entre la educación media y las familias, la educación superior y el sector productivo. Para tal fin, se conformaron 32 grupos focales - 16 de padres de familia y 16 de docentes - durante los meses de septiembre y octubre del 2015 en establecimientos educativos ubicados en los departamentos de Sucre y Antioquia.

Para efectos de este trabajo, las expectativas y percepciones se entienden como el conjunto de representaciones y valoraciones que tienen los actores sociales y sobre los cuales interpretan y elaboran juicios acerca de un fenómeno determinado (Vargas Melgarejo, 1994), en este caso, la educación media. Por consiguiente, las expectativas y percepciones son construcciones subjetivas resultado de procesos de interacción que tiene el actor social con otros. Desde esta perspectiva, no pueden ser vistas como una respuesta a un estímulo determinado, sino más bien son el resultado de un proceso complejo de socialización (Berger y Luckmann, 2005). Al ser las expectativas y las percepciones producto de la socialización, estas deben enmarcarse espacial y temporalmente y entenderse de acuerdo con las condiciones sociohistóricas de los grupos a los cuales han pertenecido los actores y en los cuales se han gestado sus procesos de socialización (García Viedma, 2011; Giddens, 1995; Vargas Melgarejo, 1994).

Bajo esta consideración teórica, se hizo el análisis de las expectativas y percepciones de padres de familia y docentes sobre la educación media. Esta posición teórica supone que ni las expectativas ni las percepciones fueron juzgadas como correctas o incorrectas. Más bien son el resultado de un proceso específico de socialización que ha llevado a padres y docentes a definir la educación media de una manera y no de otra (Weber, 1996). La virtud de este tipo de análisis radica en comprender la forma en que ciertos actores sociales, en este caso padres de familia y docentes, entienden la educación media y sobre dicho entendimiento establecen las funciones sociales y educativas de este nivel educativo, hacen observaciones o están de acuerdo con la organización actual de la educación media y mencionan cómo la educación media requiere fortalecer o profundizar 
las relaciones con las familias, con la educación superior y con el sector productivo. Por consiguiente, este trabajo se concentra en analizar los enunciados que expresan los participantes en vez de tener en cuenta el número de veces que hayan sido mencionados. Este trabajo aboga por explorar el sentido que le da cada actor a sus enunciados y de qué manera los interpretan y les dan relevancia en sus contextos particulares.

El documento está organizado como sigue.

Se presentan los aspectos metodológicos de la investigación y, luego, en la tercera sección se abordan las funciones educativas de la educación media. Además de conocer las percepciones que tienen padres y docentes sobre las funciones asociadas al ingreso a la educación superior y al mercado de trabajo, ambos actores afirmaron la importancia que tiene la educación media en la exploración de los intereses de los estudiantes, la construcción de ciudadanía y el desarrollo de capacidades. Ambos actores tienen dentro de sus expectativas que la educación media contribuya a que los estudiantes delineen sus intereses y desarrollen sus capacidades para que puedan gestionar de manera adecuada su proyecto de vida.

En la cuarta sección se presentan las percepciones que tienen ambos actores de la organización de la educación media. Se enfocan, en este caso, en la duración de la educación media, los contenidos curriculares y la edad de egreso de los estudiantes. Las percepciones son variadas y muestran la diversidad en la manera en que padres de familia y docentes definen estos fenómenos asociados con la organización de la educación media. Algunos actores consideran que la educación media debería tener tres años de duración mientras otros coinciden en afirmar que dos años es un número razonable. Otros apuntan a que los contenidos curriculares deben estar orientados al desarrollo de habilidades en matemáticas y lenguaje.

En la quinta sección se muestran las percepciones sobre las relaciones entre la educación media con la familia, la educación superior y el sector productivo. Es necesario que todos estos actores se vinculen de forma directa y más estrecha con las instituciones de educación media para así favorecer sus funciones principales.

Si bien se identificaron similitudes entre las opiniones de docentes y padres de familia en la mayoría de los temas abordados — razón por la cual el lector encontrará en diferentes oportunidades citas mezcladas de ambos actores-, en algunos casos se diferencian a raíz de la ubicación geográfica del establecimiento educativo (urbana o rural) o del carácter 
de la educación media (académica o técnica). En estos casos, el lector hallará en las secciones anteriores textos aclaratorios al respecto.

En la sexta sección se hace una síntesis de los hallazgos reportados en las secciones anteriores y se ofrece un conjunto de recomendaciones. En este último caso, las recomendaciones están fundamentadas en las propuestas que padres de familia y docentes hicieron a lo largo de los grupos focales.

\section{Aspectos metodológicos}

\subsection{Criterios para la selección de los establecimientos educativos}

Para esta investigación se seleccionaron 16 establecimientos educativos de un universo de 4.441 que ofrecen educación media en Colombia. La muestra fue obtenida a partir de los siguientes criterios:

1. Cobertura neta en educación media según regiones: Andina, Caribe, Pacífica, Orinoquía y Amazonía.

2. Ubicación geográfica del establecimiento educativo: zona rural o urbana.

3. Modalidad de educación media ofertada por el establecimiento educativo: académica o técnica.

4. Calidad del establecimiento medido mediante las cinco categorías clasificadas por el Icfes: A+, A, B, C y D y el Índice Sintético de Calidad Educativa (ISCE). Las anteriores categorías están determinadas por el porcentaje de estudiantes: $85 \%$, $65 \%, 40 \%$ y $85 \%, 15 \%$ y $60 \%$ y $30 \%$ del establecimiento educativo que se encuentren en el $33 \%$ de los resultados superiores de toda la población respectivamente a cada categoría (A+ hasta D). Por ejemplo, los establecimientos A+ tienen más del $85 \%$ de sus estudiantes en el $33 \%$ superior en al menos una de las cinco pruebas. Respecto al ISCE, está organizado en una escala del 1 a 10 siendo 10 el valor más alto que un EE puede obtener. El ISCE evalúa la calidad educativa de los EE basada en el desempeño académico, progreso en relación con el año anterior, ambiente escolar y eficiencia.

Se eligieron los departamentos de Sucre y Antioquia, en primer lugar, por estar ubicados en dos regiones diferentes a partir del criterio de cobertura neta en la educación media (Caribe y Andina, respectivamente); además, son representativos de los departamentos con menor (Sucre, 38,11\%) y mayor (Antioquia, 43,50\%) cobertura en comparación con los otros departamentos del país. En la Tabla 1 se presentan los establecimientos 
educativos que fueron seleccionados para la realización del trabajo de campo y la información de los tres primeros criterios para su selección ${ }^{1}$.

Tabla 1. Establecimientos educativos seleccionados para realizar los grupos focales

\begin{tabular}{|c|c|c|c|c|c|c|c|c|c|c|}
\hline \multirow{2}{*}{$\begin{array}{l}\text { Estableci } \\
\text { miento } \\
\text { educativo }\end{array}$} & \multirow{2}{*}{$\begin{array}{c}\text { Municipio en el } \\
\text { cual está } \\
\text { ubicado }\end{array}$} & \multicolumn{5}{|c|}{$\begin{array}{c}\text { Criterio 1: } \\
\text { Regional }\end{array}$} & \multicolumn{2}{|c|}{$\begin{array}{l}\text { Criterio 2: } \\
\text { Geografía }\end{array}$} & \multicolumn{2}{|c|}{$\begin{array}{l}\text { Criterio 3: } \\
\text { Modalidad }\end{array}$} \\
\hline & & Andina & Pacífico & Caribe & $\begin{array}{l}\text { Orino } \\
\text { quía }\end{array}$ & \begin{tabular}{|l|} 
Ama \\
zonía
\end{tabular} & Rural & Urbana & $\begin{array}{c}\text { Acadé } \\
\text { mica }\end{array}$ & Técnica \\
\hline 1 & Sampués & & & $\mathrm{x}$ & & & & $\mathrm{x}$ & $\mathrm{x}$ & \\
\hline 2 & Chalán & & & $\mathrm{x}$ & & & & $\mathrm{x}$ & $\mathrm{x}$ & \\
\hline 3 & Medellín & $\mathrm{x}$ & & & & & & $\mathrm{x}$ & $\mathrm{x}$ & \\
\hline 4 & Medellín & $\mathrm{x}$ & & & & & & $\mathrm{x}$ & $\mathrm{x}$ & \\
\hline 5 & San Juan Betulia & & & $\mathrm{x}$ & & & & $\mathrm{x}$ & & $\mathrm{x}$ \\
\hline 6 & Sincelejo & & & $\mathrm{x}$ & & & & $\mathrm{x}$ & & $\mathrm{x}$ \\
\hline 7 & Valparaíso & $\mathrm{x}$ & & & & & & $\mathrm{x}$ & & $\mathrm{x}$ \\
\hline 8 & Medellín & $\mathrm{x}$ & & & & & & $\mathrm{x}$ & & $\mathrm{x}$ \\
\hline 9 & Corozal & & & $\mathrm{x}$ & & & $\mathrm{x}$ & & $\mathrm{x}$ & \\
\hline 10 & El Roble & & & $\mathrm{X}$ & & & $\mathrm{x}$ & & $\mathrm{x}$ & \\
\hline 11 & Betulia & $\mathrm{x}$ & & & & & $\mathrm{x}$ & & $\mathrm{x}$ & \\
\hline 12 & San Vicente & $\mathrm{x}$ & & & & & $\mathrm{x}$ & & & $\mathrm{x}$ \\
\hline 13 & Jardín & $\mathrm{x}$ & & & & & $\mathrm{x}$ & & & $\mathrm{x}$ \\
\hline 14 & Andes & $\mathrm{x}$ & & & & & $\mathrm{x}$ & & $\mathrm{x}$ & \\
\hline 15 & Los Palmitos & & & $\mathrm{x}$ & & & $\mathrm{x}$ & & & $\mathrm{x}$ \\
\hline 16 & Sincelejo & & & $\mathrm{x}$ & & & $\mathrm{x}$ & & & $\mathrm{x}$ \\
\hline
\end{tabular}

Fuente: diseño metodológico del trabajo de campo, componente 5: Expectativas de padres de familia y

docentes

\subsection{Características de los participantes}

En los grupos focales participó un total de 303 personas, 172 docentes y 131 padres, madres y acudientes de los estudiantes. Todos los establecimientos seleccionados eran de educación media. Con relación a los docentes que participaron en los grupos focales, la gran mayoría eran docentes que impartían asignaturas en la educación media. En algunos casos, estos docentes también tenían responsabilidades académicas en la educación básica secundaria. En algunos grupos focales también participaron directivos docentes (rectores, coordinadores) y, en algunos casos, incluso docentes de básica primaria. Como se puede observar, no todos los docentes eran de educación media, pero esta investigación

${ }^{1}$ Para favorecer el anonimato de los participantes se presenta esta información sin el nombre del establecimiento educativo ni la aplicación del cuarto criterio. 
consideró relevante contar con las percepciones de los docentes mediante la búsqueda y recolección de la mayor diversidad de puntos posibles. Todos los participantes accedieron voluntariamente a dar sus opiniones y percepciones y firmaron consentimientos informados en los que conocieron los objetivos de la investigación, autorizaron la grabación en audio y se les garantizó la confidencialidad de sus identidades. Los participantes también diligenciaron listas de asistencia con algunos datos personales como la edad, sexo, último nivel educativo alcanzado, ocupación y, en el caso de los docentes, tiempo de experiencia docente.

En los grupos con docentes, participaron 82 mujeres y 89 hombres con una edad promedio de 41,7 años y un rango de edades entre los 27 y los 64 años. En Sucre participaron 87 docentes y en Antioquia lo hicieron 85. El tiempo promedio de experiencia de este grupo de docentes es de 18,4 años en un rango que oscila entre 1 y 41 años de experiencia docente. En el último nivel cursado, la mayoría de los docentes (72) poseen título de especialista, seguido por el título de licenciado (39), otros pregrados (33) y posgrados sin especificar el área de formación (25) (Gráfico 1).

Gráfico 1. Último nivel cursado por los docentes

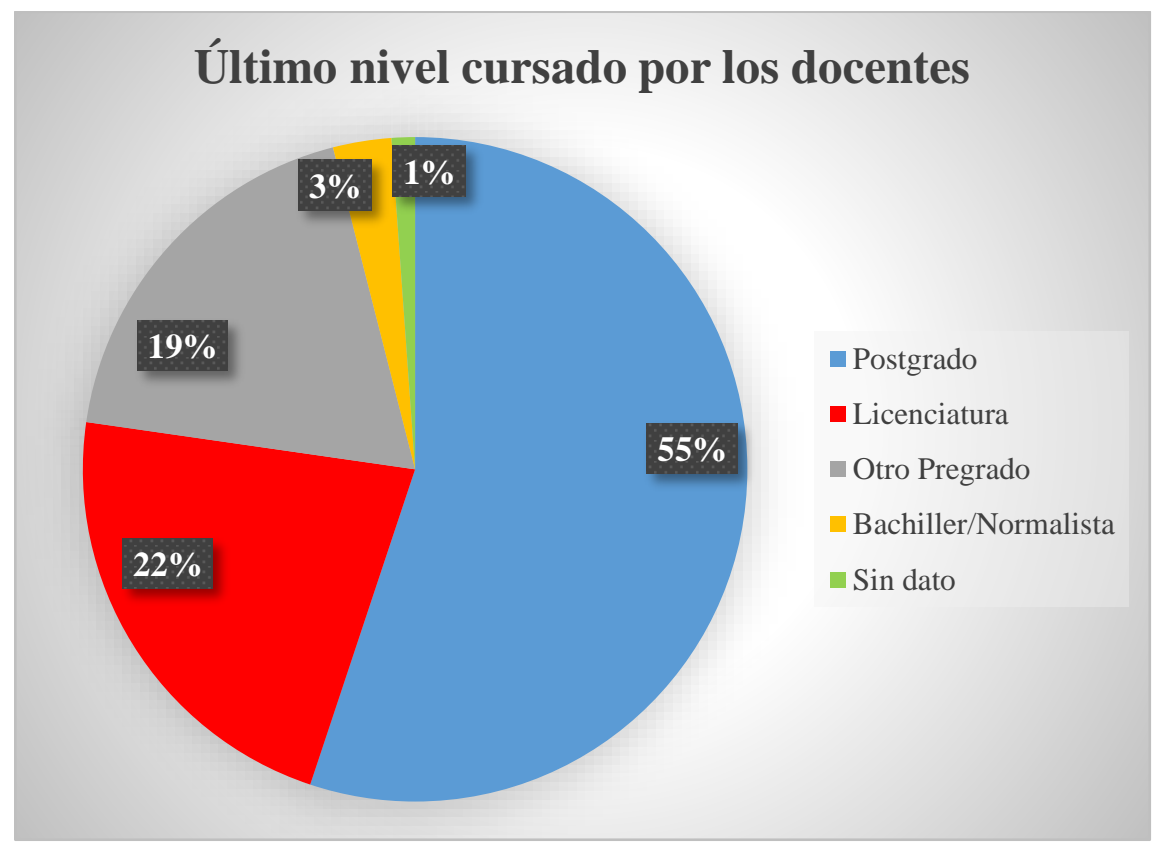

Fuente: listas de participantes de los grupos focales

Además, en los grupos focales con padres, madres y acudientes de los estudiantes, participaron 104 mujeres y 27 hombres con una edad promedio de 41,3 años y un rango de edades entre los 21 y los 67 años. Es claro que habría sido deseable tener un mejor balance entre padres y madres, sin embargo, la logística del trabajo hacía difícil garantizarlo. Adicionalmente, la realidad de las familias colombianas hace difícil saber si 
en realidad hay un sesgo; es posible que muchos de estos estudiantes estén a cargo de sus madres porque son hijos de madres solteras o porque sus padres no se involucran necesariamente en su proceso de escolarización. En Sucre participaron 75 padres, madres y acudientes y en Antioquia lo hicieron 56. El número de hijos promedio de los participantes fue de 2,8 y el rango osciló entre 0 y 8 hijos. La mayoría de los participantes (123) eran los padres o madres de los estudiantes, unos pocos (6) tenían otro parentesco con el estudiante, y tan solo 2 acudientes no tenían parentesco con el estudiante. En relación con el último nivel educativo cursado, la mayoría eran bachilleres (50), mientras que tan solo la quinta parte (25) había egresado de la educación superior como técnicos o profesionales (Gráfico 2). Por último, dentro de los participantes de los grupos focales primaron las personas dedicadas al hogar (72), seguida de empleados e independientes (38) y agricultores (10) (Gráfico 3).

Gráfico 2. Último nivel cursado de padres, madres y acudientes

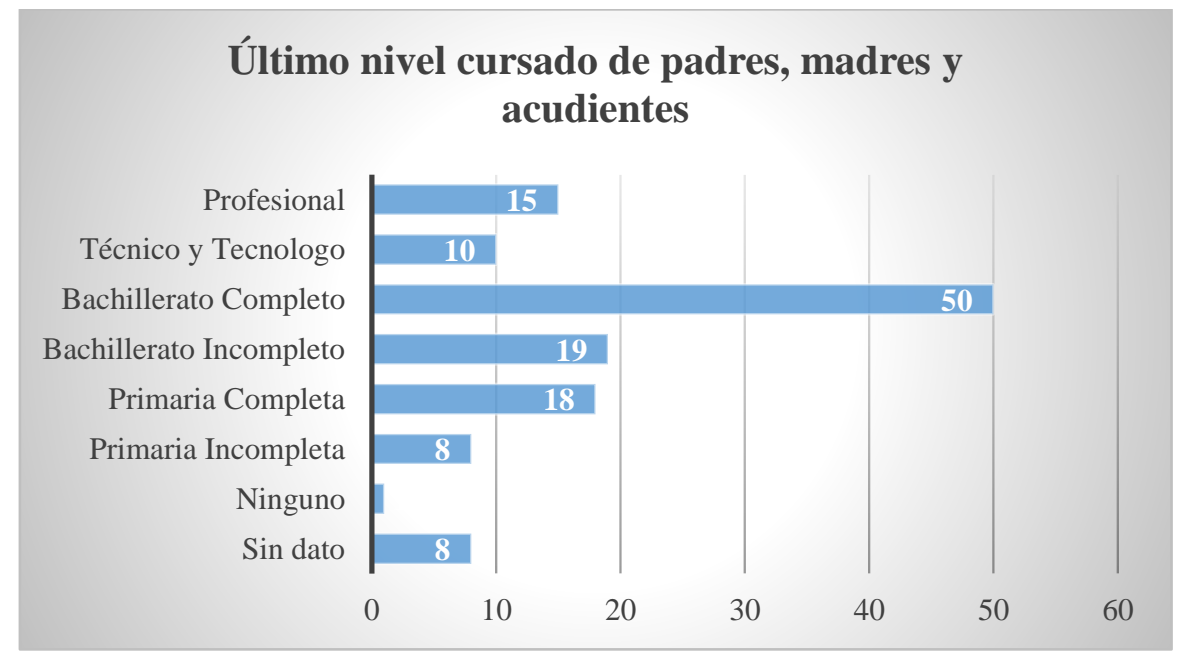

Fuente: listas de participantes de los grupos focales

Gráfico 3. Ocupación de padres, madres y acudientes

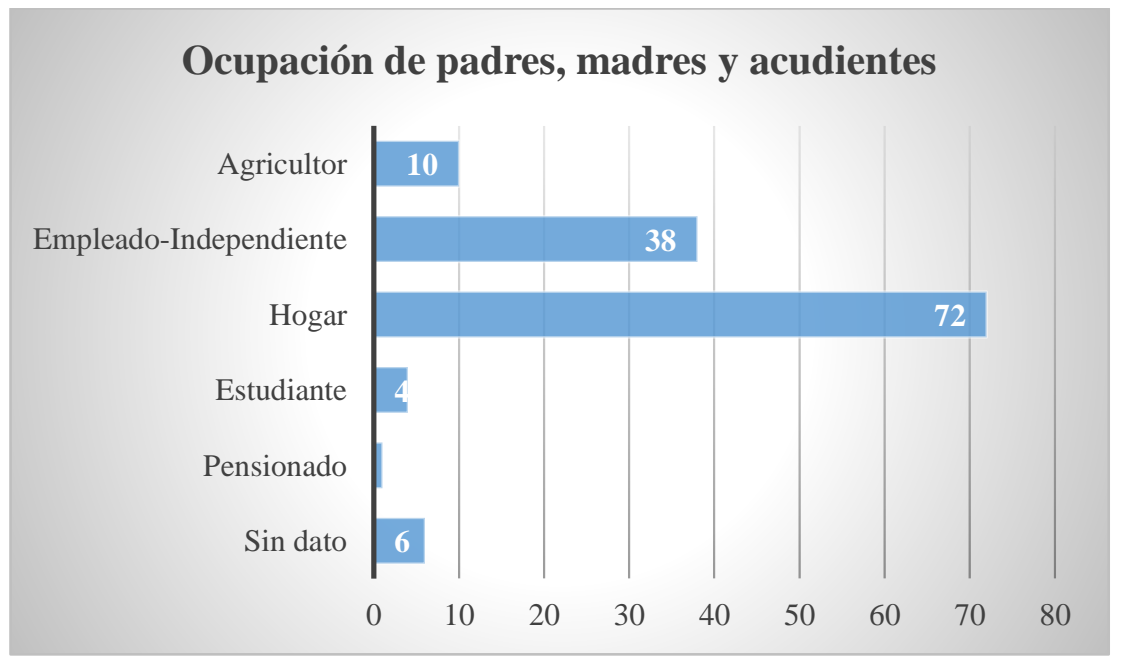

Fuente: listas de participantes de los grupos focales 


\subsection{Estrategia de recolección y análisis}

De acuerdo con Korman (1986), un grupo focal es "una reunión de un grupo de individuos seleccionados por los investigadores para discutir y elaborar, desde la experiencia personal, una temática o hecho social que es objeto de investigación”. A partir del intercambio de las experiencias de los participantes, el grupo focal busca recoger diferentes puntos de vista sobre un fenómeno particular para tener una comprensión de él. Un grupo focal es mucho más que una entrevista en grupo: se buscar poner en consideración de varias personas un tema específico con miras a que lo discutan y sobre todo que emerjan las percepciones propias de cada individuo, así como las percepciones comunes que existen en un colectivo social determinado (Aigneren, 2002; Canales, 2006; Martínez Miguélez, 2004). Así, los grupos focales son una poderosa herramienta para interpretar la manera en que padres de familia y docentes entienden la educación media en lo que se refiere a sus funciones sociales y educativas y las características de los establecimientos educativos que ofertan la educación media. El propósito fue comprender de qué manera ambos grupos de participantes perciben la educación media y a su vez comparar las similitudes y diferencias sobre las expectativas que de ella tenían estos participantes.

Se indagó acerca de las particularidades de cada establecimiento educativo y sus relaciones con las familias y comunidad educativa, el sector productivo y las instituciones de educación superior; finalmente, se identificaron las percepciones acerca de las funciones de la educación media y las expectativas de docentes, padres, madres y acudientes sobre este ciclo de formación.

Las intervenciones fueron grabadas y se transcribieron los registros de audio de acuerdo con un protocolo definido previamente por el equipo de investigadores. En este protocolo se indicaron algunas reglas generales para garantizar la calidad de los insumos de la sistematización y análisis: se siguieron algunas de las pautas de notación en la transcripción propuestas por Jefferson (2004), procurando mantener los textos con suficiente precisión para captar las diferentes intervenciones de los participantes, pero principalmente orientados a mantener la coherencia de las intervenciones para facilitar la interpretación de sus percepciones (Farías y Montero, 2005). Además, en todas las transcripciones se incluyeron cuadros de control con información general para facilitar la trazabilidad de los documentos: se registraron los nombres de los archivos digitales 
relacionados con cada transcripción (audio y texto), los datos de las personas encargadas del trabajo de campo y la transcripción e información general del grupo focal (fecha y hora, características de los participantes y el lugar de realización del encuentro y las características del establecimiento educativo en cuestión de acuerdo con los 4 criterios establecidos para la selección de la muestra).

Posteriormente, se sistematizó y analizó la información utilizando algunas técnicas básicas de análisis de contenido (Krippendorff, 1990) para la codificación y categorización, así como algunos principios de la teoría fundamentada (Glaser y Strauss, 1967; Strauss y Corbin, 2002). Se construyó un libro de códigos (Tabla 2) con base en algunas categorías iniciales y un conjunto de subtemas que guiaron el análisis (DeCuirGunby, Marshall y McCulloch, 2010; MacQueen, McLellan, Kay y Milstein, 1998). 
Tabla 2. Libro de códigos usado para sistematizar y analizar la información recolectada en los grupos focales con docentes y padres, madres y acudientes

1. Funciones sociales y educativas de la educación media: ¿para qué sirve?/¿para qué debería servir? 1.1. Funciones básicas.

1.1.1. Formación de todos los estudiantes para el ejercicio activo de la ciudadanía (derechos y deberes en sociedad, Constitución).

1.1.2. Ofrecer a todos los estudiantes las mismas oportunidades de desarrollo de sus capacidades intelectuales generales, requeridas para el aprendizaje continuo en la actual sociedad del conocimiento.

1.2. Preparación para el ingreso al mercado laboral.

1.3. Preparación para el ingreso a educación superior.

1.4. Exploración y descubrimiento de intereses: descubrimiento y desarrollo de intereses y aptitudes (intelectuales, artísticas, físico-deportivas, técnicas) que le permitan al estudiante orientarse hacia diversas opciones de estudio, trabajo y realización personal.

2. Contexto del EE (urbano vs. rural).

2.1. Ubicación geográfica del EE.

2.2. Infraestructura.

2.3. Normativa institucional (proyecto educativo institucional y manual de convivencia).

2.4. Recursos humanos.

2.4.1. Docentes.

2.4.2. Directivos (rector y coordinadores).

2.5. Características de los estudiantes.

2.6. Características de los egresados.

2.7. Características de las familias (familias en acción, restaurantes escolares).

3. Condiciones de la educación media.

3.1. Duración de la educación media.

3.2. Contenidos curriculares de la educación media.

3.3. Edad de egreso de los estudiantes.

4. El EE y sus relaciones (deben ser de dos vías).

4.1. Relación de las familias de los estudiantes con el EE.

4.2. Relaciones del EE con el sector productivo.

4.3. Relaciones del EE con la educación superior.

5. Competencias y capacidades efectivas de los estudiantes (fortalezas y debilidades de los estudiantes).

5.1. Lenguaje y matemáticas.

5.2. Segunda lengua.

5.3. Habilidades comunicativas.

5.4. Hábitos de estudio (planeación del tiempo y de las actividades).

5.5. Relaciones interpersonales con pares (incluyendo trabajo en equipo).

5.6. Destrezas.

5.6.1. Música.

5.6.2. Artes plásticas.

5.6.3. Artes escénicas (danza, teatro, baile).

5.6.4. Deportes.

5.6.5. Otras habilidades manuales.

Fuente: diseño metodológico del trabajo de campo, componente 5: Expectativas de padres de familia y docentes

Para la codificación de las transcripciones de los grupos focales se usaron las estrategias de codificación abierta y codificación axial propuestas por Strauss y Corbin (2002) y que hacen parte de la teoría fundamentada. Se inició con una lectura y etiquetamiento de los 
textos identificando las percepciones de los participantes, para luego organizar y clasificar estos códigos de acuerdo con el libro de códigos previamente establecido (Auerbach y Silverstein, 2003; Fernández, 2006; Hesse-Biber y Leavy, 2006). Durante el proceso de análisis no surgieron nuevas categorías distintas a las 5 propuestas inicialmente en el libro de códigos. Este proceso se realizó con ayuda del programa informático atlas.ti (Mühr, 2011), con el que finalmente se construyeron reportes de codificación por categorías, de los cuales se seleccionaron algunas citas para este documento.

A continuación se presentan los resultados de esta investigación, ordenados en 3 grandes ejes: 1) las percepciones que tienen ambos actores sobre las funciones sociales y educativas de la educación media y su organización y 2) las percepciones sobre las relaciones entre la educación media con la familia, la educación superior y el sector productivo.

\section{Funciones sociales y educativas de la educación media}

Tanto los docentes como los padres y madres de familia y acudientes mencionaron que las siguientes son las funciones sociales y educativas que deben ser desarrolladas por la educación media:

1. Preparar para el ingreso a la educación superior y al mercado de trabajo.

2. Contribuir al desarrollo de las capacidades de los estudiantes y, en este caso, no solamente a las asociadas a las ciencias y las artes sino a todas aquellas que son necesarias para el ejercicio creativo y responsable de la ciudadanía.

3. Facilitar el tránsito de la adolescencia a la vida adulta educación mediante la definición de un proyecto de vida que dé sentido a las decisiones que tomarán los estudiantes una vez concluyan la educación media.

Si bien las percepciones no son novedosas con respecto a lo dispuesto en el marco legal que regula la educación media, permite evidenciar que existe una sincronía con el trabajo de orientación de la educación media que hace el Ministerio de Educación Nacional y la visión de los docentes y padres de familia sobre las funciones sociales de la educación media. Estas funciones son identificadas en todas las instituciones en las que se hizo trabajo de campo. En lo que sigue se hace una descripción de estas funciones. 


\subsection{Preparación para el ingreso al mercado de trabajo}

Tanto para los padres como para los docentes es claro que uno de los objetivos fundamentales de la educación media es brindar herramientas para que los estudiantes una vez se gradúen puedan desempeñarse en alguna labor u oficio, independientemente de su ingreso a la educación superior. En este sentido, algunos actores mencionan como funciones educativas de la educación media las siguientes:

Docente: "[La educación media sirve] Para darles a los muchachos competencias laborales, $[\ldots]$ para que salgan de aquí y puedan iniciar una vida laboral” (P27: GD-A-med-iec).

Padre o madre: "Yo diría uno de sus objetivos [de la educación media, es] aprender a trabajar y madurar más, en como a saber en los oficios en los que se enfocan, saberlos hacer pues cada día me imagino yo, pienso yo" (P24: GP-A-vvjimv).

Docente: "La educación media digamos lo que lo percibo de esa manera, llevar al estudiante a una formación tal que pueda servir en un sistema, sistema productivo que se desempeñe bien en tales sistemas en este sistema que sea mano de obra educación medianamente calificada pero que no sea muy costosa así lo percibo yo" (P17: GD-A-med-ilm).

Dentro de los elementos identificados por los participantes se destaca que se deben adquirir competencias básicas para el trabajo durante el proceso de escolarización para que algunos egresados logren vincularse efectivamente con el sector productivo e incluso que estén preparados para llevar a cabo emprendimientos:

Docente: "El estado crea la educación media para la finalidad de [...] preparar o formar al educando en las competencias laborales generales, de tal manera que esas competencias [...] le sirvan a él para desenvolverse en cualquier medio, esa fue la finalidad de la educación media [...] pero yo conozco bachilleres que llegaron al bachillerato y hoy son empresarios y tiene su propia empresa, ¿por qué? porque ellos sí se formaron en esas competencias, se les dio esa formación y ellos fueron conscientes de que debían formarse y no que esté esperando al estado como patrono para que les brinde empleo, para eso crea el Gobierno eso y aún más hoy a través de la ley siempre aquí lo mencionamos la Ley 1014 que establece 
el fomento de la cultura del emprendimiento en las instituciones educativas porque ya el Estado dice ya no hay más empleo ya no hay empleo para tanta gente hay que formar a los muchachos que salgan capacitados con un aspecto emprendedor y que ellos sean ellos los que crean su propio empleo y los de su familia inclusive se queden en la región y desarrolle su propia región" (P 5: GD-S-sfr-isf).

Docente: "Con lo que salen ya han logrado construir muchas cosas: nos hemos encontrado en estos días con estudiantes, que pues ya los ve uno en su producción digamos económica muy estables mejores que uno [...] mejores que nosotros donde se sienta uno a charlar con ellos y se sienten bien están satisfechos con el estilo de vida que llevan, sus familias conformadas, o sea, [...] que la institución les ofrece una formación, no únicamente para el empleo sino una formación de personas [...] que van a servir a la comunidad y que se sirven a sí mismos, forman sus negocios, los sostienen, sostienen su hogar, sostienen sus familias, hay muchos que se han hecho cargo ya de sus padres que también es otro valor agregado. Son personas y de servir aquí pues yo creo que todos nos debemos de sentir de alguna manera satisfechos porque de acá se han llevado una buena formación" (P17: GDA-med-ilm).

Docente: "De hecho los fundamentos están claros, cierto, para adquirir a esos muchachos que tengan un poco más de conocimiento para llegar a enfrentarse a la vida laboral porque un muchacho que sale de once así sea académico mientras inicia la universidad, muchos de ellos trabajan, ya saben pues hacer un negocio, se pueden colocar ( $\mathrm{sic}$ ) a trabajar en un supermercado conocen un poco más de ley, conocen un poco más de oferta laboral y eso los empuja a emprender a emprender más" (P17: GD-A-med-ilm).

A pesar de que se reconoce que los egresados de la educación media puedan contar con competencias para el ejercicio laboral, algunos de sus docentes plantean que los contenidos abordados no son suficientes, por lo que no debería pensarse como el final del ciclo educativo, ni siquiera por aquellos que se inserten rápidamente al mercado laboral:

Docente: "Los estudiantes que rinden, esos estudiantes tiene un norte, ellos tiene las ganas de estudiar, el resto de estudiantes se limitan y aprende cualquier técnica que les permita conseguir un empleo o desempeñarse en un trabajo, y algunos tiene un negocio de fritos, una tienda, ellos van es a resolver el problema del 
empleo, una vez que ellos tengan en el empleo, para ellos se resolvió la vida" ( $\mathrm{P}$ 7: GD-S-slg-tag.).

Docente: "Hay un contexto de la educación, del Ministerio de Educación Nacional, está descontextualizado, porque ya con un noveno, no le sirve para nada, antes con un noveno grado se podía aspirar a ingresar al SENA, cierto que es que el SENA era como esa posibilidad que tienen los estudiantes, como para revisar en una técnica o algo así cierto pero era muy difícil que eso, en un noveno grado no te da a ti para nada, ahora. El bachillerato toma mucha influencia como para entrar a la universidad, pero tampoco es que radique mucho. Un muchacho con un bachiller no es realmente no es competentemente laboral" (P19: GD-A-medipb).

En los establecimientos educativos rurales se discutió ampliamente el problema de la modalidad técnica agropecuaria y la necesidad de replantearla de acuerdo con los retos que impone el contexto actual, particularmente el problema del desempleo y falta de oportunidades en el campo y las expectativas de los jóvenes de migrar a las ciudades:

Docente: "Este colegio es agropecuario cuando ya estoy aquí y tengo veinte tantos años de ser agropecuario, es técnico agropecuario y desafortunadamente los estudiantes que salen de acá, pues no salen con este fuerte de técnicos agropecuarios. Primero porque en la región por la inclemencia del clima pues ha hecho acabar a los ganaderos, a las empresas ganaderas y pues ellos no tienen fuentes de empleo para tal fin, generalmente los estudiantes egresados de acá los ve uno trabajando en construcción, algunos [...] realizando trabajos informales, vendiendo productos haciendo cualquier otra cosa, menos para lo que estudiaron. [El problema] no son los contenidos porque los contenidos son únicos, son nacionales los contenidos son políticas del Ministerio de Educación Nacional, entonces lo que ha pasado aquí es falta de oportunidad cuando los egresados van al mercado, falta de oportunidad que no hay trabajo para que ellos puedan ejercer su labor como bachilleres agropecuarios" (P13: GD-S-pal-cdr).

Sin embargo, en algunos establecimientos educativos los participantes resaltaron el sentido de pertenencia que aún tienen los jóvenes con el campo, algo que debe tenerse en cuenta al pensar en volver a él como opción laboral: 
Docente: "Es que hablando con ellos no encuentra uno [profesor] es los muchachos puedo especular pero yo diría el sesenta o setenta por ciento de los muchachos de este colegio todavía quieren el campo, o sea todavía se sienten del campo, no es el estudiante que 'hay yo voy a terminar para irme de la finca porque quiero ir a la ciudad porque quiero abandonar’, ¡no! hay mucho joven de acá que ven como su proyecto de vida, así de pronto como su proyecto, porque de pronto de la educación nosotros lo vemos como mal que es que no vayan a la universidad. Pero ellos su proyecto de vida lo asumen en el campo eso es, $[\ldots]$ parece extraño que tengamos que volver al campo volverlo tecnificar yo le decía a ellos: 'no es el estudio muchachos, no es para que se vayan para la ciudad, vayan estudian y vuelvan' y es otra cosa que nos toca a nosotros los docentes, no es desenamorarlos del estudio enamorasen del estudio del estudio pero vuelvan al campo eso es una fortaleza de ellos los muchachos aquí todavía se sienten campesinos y se sienten orgullosos" (P23: GD-A-vvj-imv).

Padre o madre: "Yo diría que es como para ellos descubrir que, como qué carrera o qué estudio lo enamora más para tener un conocimiento más haber (sic.) que se proyectan de vida para ellos, me imagino yo que podría ser. [...] Por ejemplo los que salen de acá muchos de acá se quedan en las fincas administrando sus fincas, los papas bien ancianitos y ellos organizando sus fincas, porque ya saben, desde el modo de sembrar un palo de café, el plátano, tienen todas pues imagínese es hermoso el que se queda en la finca administrando la finca con el papa, qué más estudio que ese" (P24: GP-A-vvj-imv).

Padre o madre: "Eso $[\ldots]$ le decía yo a un señor $[\ldots]$ le decía $[\ldots]$, que vamos a hacer [...] porque mire pues a los muchachos los hijos pues de nosotros van creciendo y van buscando pues su futuro en la universidad, entonces aquí quien me va a quedar en el campo, nosotros bien viejos que ya no somos capaces de sembrar unas papas, eso se va a quedar aquí sin quien produzca comida" (P18: GP-A-med-ilm).

Como una manera de hacer más pertinente la formación en la zona rural, se menciona la inclusión de nuevas tecnologías de la información que permitan la modernización del campo y la tecnificación y actualización del campesinado:

Docente: "Lo que no motiva es la forma como se está practicando, pero si llegan nuevas tecnologías donde yo pueda adicionar nuevas formas de producir la tierra, 
sin estar como el campesino a suelo, ahí sería otro recurso. [...] lo que pasa es que se crean esas acciones agropecuarias sin tener una orientación de las mismas se crea un nombre como tal pero no hay un estudio donde diga: para nosotros tener una orientación agropecuaria son necesarias estos elementos, además de lo curricular, elemento, insumos, donde el estudiante vea como se puede poner a producir la tierra pero sin esa esclavitud agropecuaria. [...] con procesos agros industriales, con equipamiento, adecuado" (P 7: GD-S-slg-tag).

Padre o madre: "Por ejemplo yo digo nos estamos quedando sin con quien trabajar, todos se van para Medellín. Todos para Medellín, para que la gente como que se motive más se enamore del campo, porque es que el futuro está en el campo, los estudiantes terminan el bachillerato y se van para la ciudad que dizque a buscar el futuro y no saben que el futuro esta es en el campo" (P24: GP-A-vvj-imv).

En contrapartida, algunos participantes aducen que el problema de falta de pertinencia de la formación que reciben los estudiantes se debe a la ausencia de terrenos propios para los cultivos o el temor a endeudarse para ponerlos a producir cuando se cuenta con ellos:

Padre o madre: “[...] no la mayoría no tienen finca, entonces cuando ellos salen estudiantes, técnicos agropecuarios buscan otra cosa que hacer como enfermería, modistería buscan otras cosas diferentes, usted sabe que para que haya progreso en el agro se necesita [...] de un terreno y nosotros eso no tenemos" (P 8: GP-Sslg-tag).

Docente: "Algunos cuentan con sus papás que tienen parcela, pero no son capaces de sembrar, porque no quieren, pero también es bueno ayudarlos a que no tengan miedo a pedir esos nuevos proyectos que son de capital semillas, les da miedo es cuando escuchan tantos millones por que si les sale mal tienen que devolver tantos millones, entonces ellos tienen que perder el miedo y llevarlos a pensar de manera empresarial, como hacemos nosotros como institución, tendríamos que conseguir un terreno, y eso es imposible, hay que generarles la motivación que ellos puedan tener ideas sobre ello" (P 7: GD-S-slg-tag).

\subsection{Preparación para el ingreso a la educación superior}

Otra postura generalizada entre padres de familia y docentes - tanto en establecimientos educativos rurales y urbanos y de carácter académico y técnico - es que los egresados de la educación media deben contar con suficientes competencias para acceder 
inmediatamente a la educación superior sin importar si son programas técnicos profesionales, tecnológicos o universitarios. Esta mirada está presente tanto en docentes como en padres de familia:

Docente: "Los estudiantes que salen de aquí de la educación media salen preparados para las universidades por lo menos nosotros lo estamos haciendo los de aquí hablo de nuestra institución" (P 3: GD-S-lpc-ilp).

Docente: "Cuando comenzó la educación media comenzó solamente propuesta para que todos [los estudiantes ingresaran a la formación] universitaria y eso es lo que está sucediendo" (P 1: GD-S-cha-iec).

Docente: "Si están llegando ya una gran proporción de estos estudiantes a la universidad, algunos desgraciadamente inician y por recursos económicos se salen otros porque no aguantan pero aquí lo fundamental y yo se lo decía al profesor es que hay que motivar a los pelaos no es que se van a quedar o que tengas tu microempresa y te quedes vendiendo diabolines en la esquina, no, hay que buscar cómo entrar a la universidad porque yo les digo que el pregrado ahora es el bachillerato de los ochenta" (P11: GD-S-bet-sjb).

Padre o madre: "Que salgan con la visión de que tienen que seguir adelante [...] profesionalizarse, no quedarse ahí termine once y ya me voy a quedar en mi casa no!, meterles en la cabeza que el futuro está en sus manos que ellos tienen la posibilidad de una u otra forma de seguir estudiando no quedarse ahí en el paso" (P 2: GP-S-cha-iec).

Dentro de esta postura, la media también debe ayudar a los estudiantes a elegir sus intereses académicos y gustos profesionales:

Padre o madre: "Ellos solos van haciendo su elección de acuerdo a lo que les guste [...] por ejemplo la hija mía quiere estudiar es que odontología, y ella dice que esa, que esa que aquí no la da en esta universidad no la dan pa' ella seguir acá, que tiene que ser en Medellín” (P21: GP-A-vba-irc).

Padre o madre: "Ya el muchacho ya tiene que ir madurando [...] lo más importante es la táctica con la que usted aborda al niño al que va creciendo y al joven y (sic) irle metiendo en la cabeza el cuento como es. [...] La media vocacional es cuando usted llega a diez y once que es cuando usted se encuentra las áreas más elevadas, generalmente usted no veía química en noveno lo veía en diez y once, ya ahorita 
desde noveno y es más, se debería ver desde sexto, para que los niños vayan encontrándose en el cuento en el tema de cómo es, van escudriñando de cómo es en cada una de las áreas y él vaya despertando el interés por determinada carrera universitaria" (P30: GP-A-med-imd).

Docente: "[...] yo soy profesor de emprendimiento y (sic) hice un test sobre digamos dirección vocacional de los muchachos y uno se encuentra que hay muchachos que les gusta la psicología, les gusta la medicina, les gusta la administración, sin desconocer también que este es un colegio agropecuario.[...] para que los estudiantes de diez y once tengan contacto con la universidad sin necesidad de que yo termine once y diga bueno yo después de aquí para donde cojo , no allá la universidad en diez y once, es para que diga me voy a meter acá, especie de semillero, entonces se le procede la palabra y entonces de hecho cuando el estudiante salga de once ya este direccionado, no es pararme aquí y decir después para donde cojo, oiga esto es direccionado, vaya y mire haga semilleros de matemáticas, de humanidades, de todo lo que oferta. Entonces oferta que tiene la universidad y ya" (P23:GD-A-vvj-imv).

Quienes defienden más fuertemente esta idea, sugieren que la educación media no es más que otro escalón en el recorrido académico del estudiante, por ello debe facilitar el ingreso y permanencia en la educación superior:

Padre o madre: "Para mí el objetivo general de la educación media es que el estudiante salga con una buena preparación para que cuando llegue a la universidad, este, no pase tanto trabajo porque ahí es donde se ven las falencias [...] entonces que pasa que la educación secundaria pienso yo que se debería reforzar más, enseñar más, se debiera preparar más al estudiantado para que cuando llegue a la universidad este no pase tanto trabajo y que sea buen profesional" (P10: GP-S-smp-imv).

Docente: "La educación media digo de pronto que no es para cambiar la vida en la parte económica de una persona, yo diría que la educación media es un medio para continuar y llegar alcanzar un nivel académico superior, eso es la educación media es el puente para continuar y llegar a la educación superior. [...] la educación media quedó para ser bachiller y que para qué sirve ser bachiller, en ciertos casos para de pronto acceder a un puesto como aseador, como celador, de pronto ehh si tiene las aspiraciones y si es posible y eso sí pasa, pueda acceder a 
la policía pero para continuar como ejerciendo como en cualquier otro oficio muy difícilmente $[\ldots]$ entonces de pronto no es tanto que la educación media sirva para que la persona tenga un cambio de vida en la parte económica, que de pronto es el medio para continuar? Sí, es un puente para continuar" (P5: GD-S-sfr-isf).

Sin embargo, el acceso a la educación superior suele requerir mucho más que unas competencias adquiridas durante la educación media. A pesar de que muchos entienden a la educación media como la antesala a la educación superior, para muchos egresados sus expectativas de continuar estudiando se ven frustradas por dificultades económicas e incluso académicas. Para lograr acceder a la educación superior, los estudiantes deben primero superar satisfactoriamente las pruebas de estado (Pruebas Saber 11). Sin embargo los docentes y padres mencionan que es muy difícil para los estudiantes en la zona rural y que cursan la educación media técnica obtener un puntaje que los habilite para ingresar a la educación superior:

Docente: "Los muchachos de acá por el estrato, por la situación socioeconómica en la que están, no pueden aspirar a una universidad privada porque no tienen los recursos, entonces les queda la universidad pública y qué pasa, para entrar a una universidad pública hay un examen de admisión que muy difícilmente estos muchachos lo pasan, por qué, porque es que se necesitan los conocimientos que hayan obtenido durante todo el tiempo de su formación, no lo que hayan aprendido del año pasado, a la fecha [...] entonces a la fecha no pasan en universidades públicas [...] entonces listo, no pueden, no pasan el examen de admisión a la universidad de Antioquia o a la Nacional, porque es un examen muy exigente además que a Medellín confluye gente de diferentes departamentos entonces imagínese [...] la competencia es dura! Por otro lado entonces se oye mucho hablar del fondo EPM, el fondo EPM existe, da unas becas, pero que pasa, con este que le llevamos a los de once a mostrar es todos los requisitos no se juntan todos los requisitos, los muchachos si están en los estratos cero, uno, dos hasta tres tiene el fondo EPM, pero no les da su promedio, su puntaje, sus notas no les da, porque es un pelado tiene que ser consciente y estudiar desde sex to pues tratar esmerarse, ser buen estudiante, porque las pruebas Saber no son fáciles, inclusive a uno a veces que le toca cuidar, uno dice ve esta vaina esas cosas que uno como maestro también queda echar cabeza, entonces es muy difícil, así que los muchachos no pueden en realidad hacerse beneficiarios [...] de esos fondos, de esas becas, de 
esos incentivos. ¿En qué se quedan?, los muchachos se quedan simplemente como bachilleres" (P27: GD-A-med-iec).

Por otra parte, en la mayoría de las sesiones grupales se mencionó la necesidad de incentivar el ingreso de los jóvenes a la educación superior ya sea a través de becas o estímulos económicos como el programa "Ser pilo paga". En este sentido los padres mencionan:

Padre o madre: "Para mejorar el nivel académico, para mejorar la calidad de vida, que nos ayuden a los más pobres, que el Estado ayude a darle ayuda a uno para que los hijos de que a los jóvenes los ayuden como con becas, como con préstamos y eso que el gobierno [aporte]" (P 6: GP-S-sfr-isf).

Padre o madre: "Posibilidades, pues porque ellos son inteligentes y se ganan becas, en la de Antioquia que es pública [...] por ejemplo, aquí me he dado cuenta que aquí es como unos padres como una cosa de la iglesia, hay una cosa de la iglesia no sé quiénes son que le ayudan a los muchachos por qué se han ido a estudiar filosofía, profesores, y se han ido becados como con unos sacerdotes, no sé, la universidad Luis Amigó, que es una línea católica de los padres [...] y vienen de Medellín acá y los invitan y los llevan allá, hasta a Bogotá se han ido acá hay niños que se han ido hasta Bogotá de acá y por ejemplo un primito mío que salió de acá del bachillerato lo cogió pues salió bien de las pruebas del Icfes salió con educación media beca para la universidad católica de Rionegro, está estudiando derecho allá" (P18: GP-A-med-ilm).

Para los docentes, los estudiantes con bajos recursos se desmotivan incluso con solo pensar en el acceso a la universidad, por lo que las becas parecen ser la única opción aunque se sabe que muy pocos pueden acceder a ellas:

Docente: "Entonces tenemos solamente los ricos [que pueden financiar su educación], y donde están los de bajos recursos, porque si los de bajos recursos les dicen, les prestamos, los diez millones para que estudie y después cuando usted trabaje me los paga y en que quedo. Yo pienso que esa parte hace que se desanimen más" (P23: GD-A-vvj-imv).

Docente: “[...] es muy difícil entrar a la universidad como muy caro, mire que el tiempo [...] y lógicamente los costos, los costos que tiene la universidad para tener acceso" (P23: GD-A-vvj-imv). 
Padre o madre: "por lo menos que va a hacer la hija mía que está haciendo once e hizo hasta once que hizo las pruebas, se está preparando para las pruebas del Icfes y yo sé que no me van a dar una beca tengo que esforzarme por mi misma para yo poder seguir así me dice" (P 2: GP-S-cha-iec).

Además, algunos docentes vinculan el problema de la limitación del acceso a la educación superior por ausencia de recursos económicos con los bajos resultados obtenidos en las pruebas de Estado:

Docente: "Entonces ahí llega la frustración de ellos cuando dicen vea el estrato me da, el colegio es oficial me da, no he recibido ningún tipo de auxilio eso también ahí cuenta, pero el problema es cuando vemos los resultados, profe ahí si no nos ayuda ese puntaje, entonces yo digo, no es, no estoy de acuerdo con lo que dice [profesor] con que es que la mayoría no quieren no, la mayoría no, es obvio que van a ver unos casos que no sé, que no están ahí, o sea de treinta, cómo le digo, ocho muchachos como que no les interesa, pero que pasa con los otros veintidós los otros veintidós si quieren, el problema es que no ven la facilidad para acceder por donde acogersen (sic) para lograr el beneficio" (P27: GD-A-med-iec).

Pero los problemas no terminan al lograr ingresar a la educación superior. Los participantes señalaron que la deserción en la educación superior es una realidad que no solo está relacionada con el problema de los recursos económicos, sino también con la falta de claridad en el proyecto de vida de algunos egresados de la educación media que salen muy jóvenes e inmaduros y carentes de una sólida formación que les permita afrontar el proceso de escolarización en la educación superior:

Docente: “Todavía están muy inmaduros todavía no tienen esa madurez de saber hacia dónde quieren encaminar su vida, qué profesión deben de tomar, ¿sí?, entonces ahí vemos que en las universidades en el primer semestre, segundo semestre, muchos niños se quedan estancados, no les gustó la carrera, no quieren continuar, pero es por lo mismo porque a lo mejor ellos visualizan algo y cuando llegan allá están, caen en cuenta que no es eso no es lo que esperaban” (P 5: GDS-sfr-isf).

Docente: “[...] entonces los veo perdidos, ¿en qué sentido? porque usted les pregunta a ellos qué quieren ser, qué quieren hacer, y resulta que todos quieren ser o hacer profesiones, que de pronto les dé dinero, que les dé poder, que les dé 
fama, es decir, tienen unos paradigmas muy diferentes a los valores tradicionales, no diríamos que en todos sino en la gran mayoría, se presentan a universidades y lo digo porque los escucho y hay docentes universitarios y allá me los encuentro y se presentan a universidades donde hay carreras precisamente que le va a dar dinero, le va a dar estatus o mil cosas, y ahí es donde uno ve una cantidad de estudiantes fracasados, por ejemplo se presentan a la Universidad de Antioquia, de los poquitos que pasan a la Universidad de Antioquia solamente el cuarenta y ocho por ciento llegan a graduarse si, ¿dónde se quedan los otros estudiantes de la universidad o un poco más entran en proceso de deserción y por qué entran en proceso de deserción? porque no fue mi carrera, porque no llenó mi expectativa, no es lo que quiero, entonces, o sea que estos estudiantes llegan allá, empiezan un proceso de que no hay posibilidades de dinero, del prestigio, y resulta que se bloquean allá, es decir, ven que la cosa es otro asunto muy diferente y ahí esta pues este asunto de la deserción, increíble lo que se presenta en todas las universidades, en las universidades del país, en eso que entran en proceso de deserción, y que se ponen hacer, actividades que de pronto no son los esperadas por la sociedad, o se quedan simplemente como obreros ganándose el dinero del día a día, pero no se proyectan, no se proyectan porque así lo muestran las estadísticas, entonces veo jóvenes que no saben lo que quieren, ¿qué pensaría yo que la educación secundaria y educación media?, debe fortalecer esos procesos un proyecto de vida en fortalecer valores de los jóvenes donde ellos en verdad vean en el conocimiento una posibilidad o un estilo de vida, no sé, pero es un proceso muy complejo" (P29: GD-A-med-imd).

Padre o madre: "Yo creo que nuestros alumnos, nuestros niños deben de cuando salen del colegio deben de estar un poquitico más preparados para cuando lleguen a la educación superior, allá se van a encontrar con cosas diferentes a como son aquí, siquiera que se hagan una noción, para que ellos pudieran demostrar alguito allá y no los cogieran tan de repente para ver las cosas, allá llegan a un mundo nuevo, otro mundo diferente de pronto a veces [...] los colegios que salen esos niños para la universidad al principio les va bastante mal uno ve las notas son bastante mal, y están repitiendo quedaron con una o dos materias no tan malas y eso es plata que $[. .$.$] también pierde uno porque para rehabilitar una materia y que$ cada pagar una cantidad de plata entonces se necesita como un apoyo más en los 
colegios [...] para cuando ellos vayan a la superior que tuvieran más entendimiento" (P12: GP-S-bet-sjb).

El problema del desempleo es también abordado, ya que no solo afecta a los egresados de la educación media, sino también a los profesionales recién graduados de la educación superior:

Docente: "[...] es muy triste, primero el estudiante cuando llega a la universidad y hay deserción por mil causas y, lo otro que es que si es verdad muy difícil lo vivo a diario en la Universidad de Antioquia: por ejemplo, estudiantes que entran a la universidad con la ilusión que estudie, que lo que vale es el estudio estudiantes con mil dificultades con su carrera salen no hay empleo familias que están en expectativa porque mi hijo es ingeniero, médico, abogado y están ya esperando que ya se van a colocar y pasan dos, tres, cuatro años y la familia esperando de que bueno ya mi hijo que es un profesional resulta que no eso era antes que usted salía de médico e inmediatamente, abogado inmediatamente, hoy estamos llenos, (en Medellín específicamente, no sé cómo será en otros países, ciudades) de ingenieros los que usted quiera, abogados, contadores, médicos bueno en fin desempleados entonces la realidad es muy triste cuando la expectativa familiar de tener un hijo profesional para mejorar su calidad de vida se va a pique" (P29: GDA-med-imd).

En los establecimientos educativos rurales se identificó un problema adicional: las ofertas de educación superior están limitadas a las ciudades, son inexistentes en el campo. Por esta razón, si los egresados de este tipo de establecimientos quieren acceder a la educación superior, deben incurrir en gastos adicionales como desplazamientos y manutención dificultando mucho menos el tránsito hacia la educación superior:

Docente: "La oferta es limitada en la región: entidades como la Universidad de Antioquia y el Tecnológico de Antioquia han venido diversificando las carreras que se presentan y ofreciendo más programas, no obstante, se quedan corticos todavía porque mucha gente tiene que migrar a la ciudad para estudiar las carreras que les gusta" (P22: GD-A-vba-irc).

\subsection{Formación integral en valores y descubrimiento de aptitudes}

La educación media no solo busca una formación instrumental (laboral o académica), sino que también es percibida como el espacio para que los estudiantes exploren sus 
intereses con miras a desarrollar habilidades y aptitudes particulares. Este periodo también es crucial para la formación en valores ciudadanos necesarios para la convivencia social pacífica.

\subsubsection{Exploración y descubrimiento de intereses}

Los participantes sugieren que los estudiantes de la educación media deberían poder elegir temáticas o áreas optativas en las cuales profundizar (énfasis) de acuerdo con sus intereses particulares y no solamente a una oferta académica determinada. Algunos participantes plantean que estos énfasis deberían estar disponibles desde la educación básica primaria y no esperar a que los estudiantes ingresen a la educación media:

Padre o madre: "Énfasis en algo, $[\ldots]$ sí, porque en la educación media salen es a la deriva, están estudiando es porque estamos estudiando es ya, mientras que si quiera un énfasis ellos estarían pensando yo quiero estudiar esto, quiero hacer aquello, y si están metidos en un énfasis por ese caminito se van” (P26: GP-Acab-ifc).

Docente: "Yo pensaría que no sería únicamente la educación media seria desde que inicia la actividad escolar donde se debe rescatar esas donde a que a ellos les gusta como encaminar al muchacho hacia donde él quiere llegar buscar como el propósito las cosas que él tiene también no desde la educación media si no de la básica desde que salen a escolar que vaya encaminado a lo que a él le gusta hacer" (P25: GD-A-cab-ifc).

Desde esta perspectiva también se debe trabajar con los estudiantes para que a partir de sus gustos e intereses logren articular su proyecto de vida:

Docente: "Vea yo fui el director del grado once, el año pasado [...] fueron quince estudiantes de esos quince estudiantes tengo reporte más o menos de seis, de nueve estudiantes que están en la universidad y de dos que están en tecnologías de esos quince estudiantes. Yo adelanté con ellos en grado diez y once un proyecto sobre fortalecimiento psicopedagógico logramos hacer un convenio con la cooperativa que nos patrocinaron dos psicólogos para hacer unos tallercitos con ellos acá en el colegio los días sábados. Apenas se va haciendo el balance veo que algo se movilizó porque cuando ellos salieron no salieron otras prevenciones, pero cuando uno ya los ve en la realidad los ve metidos en lo que se quería" (P17: GD-A-medilm). 
Docente: "Yo lo veo como un complemento nosotros de pronto vemos que los muchachos debemos enfocarlos hacia algo si, entonces nosotros el proyecto de vida más que todo es que como el muchacho vaya paso a paso tratando de definir que pretende él con su vida entonces yo lo veo más como un complemento que de pronto decir que le falta yo lo veo como complemento del quehacer" (P22: GDA-vba-irc).

Para los docentes es claro que este trabajo debe ser constante durante toda la educación que reciben los estudiantes desde la primaria hasta la educación media:

Docente: "Yo tuve la ventaja de trabajar en otros colegios y eso es cultural, empecemos por eso es cultural la parte cultural de aquí de [esta institución] es muy diferente a la parte cultural de otros colegios aquí por ejemplo desde sexto se le machaca al estudiante el tema de la expresión, de la autocrítica reflexiva y que sean responsables y los estudiantes de bachillerato van se van construyendo y van adquiriendo una mayor responsabilidad" (P19: GD-A-med-ipb).

Docente: "Realmente aquí los pelados carecen de un proyecto de vida y muchos de los que están aquí vienen por que los padres les dicen que tiene que ir, pero ellos no están convencidos que la educación realmente es lo que aporta a su calidad de vida" (P 7: GD-S-slg-tag).

\subsubsection{Formación para el ejercicio activo de la ciudadanía}

Los participantes argumentan que los estudiantes deben estar en capacidad de comprender y criticar los distintos valores que regulan la vida social (tolerancia, respeto, entre otros), de tal manera que puedan ejercer posteriormente con responsabilidad su ciudadanía. Estos valores se consideran importantes dentro del proyecto de vida de los estudiantes:

Docente: "Estamos desarrollando un proyecto que ya se llama proyecto de vida donde pues se trabajan todo lo que son valores, principios, todo pues es un proyecto bien estructurado donde se ha tomado, se partió de cero, partiendo del diagnóstico que se hizo la problemática que nos podía causar problemas más adelante estamos atacando a través de esos proyectos" (P22: GD-A-vba-irc).

Docente: "La educación media tiene una serie de caracterizaciones, se desglosan en sí de los fines que tiene la educación media, que está establecida en lo general, hay fines de carácter ontológico, hay fines de carácter humanístico, hay fines racionalistas también, entonces lo que nosotros tenemos que buscar [es la forma 
de] darle como participación a cada una de esas esferas que tiene la persona: la parte humana por ejemplo, $[\ldots]$ el funcionamiento de $[\ldots]$ la parte valorativa, de sus ideales, [...] de sus expectativas de vida. [...] A veces hay estudiantes que sé que no van a ir a la universidad, pero quieren tener una orientación sobre lo que van hacer, después de que salgan de aquí. [...] Hay estudiantes que se entristecen cuando están llegando a grado once porque comparten gran parte de la vida que han hecho [...] y otros que no saben qué hacer. [...] Y inclusive hay unos que son tan mercenarios que dicen no ya yo salí de acá de las instituciones pero no, ya no importa lo que, lo que vaya a pasar de aquí en adelante. Entonces es también tratar de ver esas características que tenga el estudiante, del punto de vista académico, del punto de vista de sus valores y actitud. [...] Y tratar de organizar así como su profe, de tal manera que pueda ser orientado eficazmente a una toma de decisión" (P 9: GD-S-smp-imv).

Además, el ejercicio de la ciudadanía implica tener una fundamentación conceptual en torno a temáticas como derechos y legislación cuyo conocimiento supondría mejores comportamientos en el futuro:

Docente: "Y entonces ahí hay un asunto y es que nos estamos dándole una cantidad de información a los estudiantes y no estamos pensando y no estamos formando ese sujeto político que es el que pide el Estado el que necesita el Estado" (P29: GD-A-med-imd).

Padre o madre: "Si somos educados, ¿por qué nos matamos a veces, por qué somos violentos? por la ignorancia, si fuera más preparada más estudiada podemos [llegar a ser] más accequibles (sic), más tolerantes” (P18: GP-A-med-ilm).

\subsubsection{Ofrecer oportunidades para el desarrollo de las capacidades de los estudiantes}

En los grupos focales se les preguntó a los participantes acerca de las habilidades y capacidades académicas y no académicas que los estudiantes desarrollan durante la educación media. Es frecuente la mención de la inclusión de espacios deportivos como estrategias pedagógicas para la formación en valores e incluso para plantearles a los estudiantes alternativas de vida diferentes a la convencional carrera técnica o profesional:

Padre o madre: "Por ejemplo [barrio en el que está ubicado el establecimiento educativo] no hay una canchita hay muchas niñas de acá de la institución que están 
en el equipo femenino de fútbol, inclusive aquí hay una niña de once que es delantera del equipo femenino de [municipio]" (P21: GP-A-vba-irc).

Padre o madre: "Deportiva pues este año, [...] un joven de aquí del pueblo hizo una escuela de fútbol entonces tiene siempre a bastantes jóvenes y niños y niñas pequeños que pues tiene de lunes a viernes horarios en la tarde, entrenando dos horas, y ahí y también hacen torneos [...] fútbol, microfútbol, la escuela es de fútbol" (P26: GP-A-cab-ifc).

Docente: "Ahora he escuchado algunos estudiantes que están formando escuela de fútbol aquí dentro del pueblo se están buscando en [municipio] van a los otros a jugar es decir aquí en las tardes ya están practicando deporte” (P 3: GD-S-lpcilp).

La inclusión de actividades artísticas en la cotidianidad de los estudiantes también se plantea como una posibilidad para la formación de la autonomía que puede ser impulsada dentro y fuera de la escuela:

Padre o madre: "Bueno yo tengo es una niña y está en décimo, está estudiando mecánica Industrial, fuera de eso ella es de la sinfónica intermedia de Medellín, ¿qué resalto? el sentido de la responsabilidad, son muy autónomos, son muchachos que 14 y 15 años la mentalidad útil son comparadas con otras" (P20: GP-A-med-ipb).

Docente: "Nosotros lo que tenemos es hemos tratado de acuerdo con las habilidades que nosotros tenemos es de trabajarles las habilidades [...] artísticas o sea el profesor por ejemplo que canta entonces él tiene su partecita de música con los que les gusta eso tratamos siquiera una horita a la semana, ella que baila entonces ella los pone a bailar y a danzar a mí que me gusta el teatro entonces hay grupitos que quieren estar en teatro" (P17: GD-A-med-ilm).

También los padres y docentes mencionaron algunas fortalezas particulares que veían en sus hijos y estudiantes de la educación media, dentro de las que se pueden destacar: creatividad, habilidades en matemáticas, en inglés, en ciencias sociales y en informática.

\section{Organización de la educación media}

Según lo dispuesto en el marco normativo que regula educación media (Congreso de la República de Colombia, 1994), esta comprende 2 años y los estudiantes egresan a los 17 
años. Para algunos participantes esta duración no es la más adecuada y mucho menos la edad en que se gradúan los estudiantes. Pero también hay participantes que están de acuerdo con esta manera en que se organiza la educación media.

\subsection{Duración de la educación media}

En relación con la duración de la educación media, algunos docentes y padres de familia plantearon la necesidad de extenderla con miras a que los estudiantes desarrollen plenamente sus potenciales, se consolide la articulación entre la educación media y la superior y la formación para el trabajo. Dos docentes proponen que existan grados adicionales en un esquema similar al de las escuelas normales u otras escuelas que se enfocan en oficios lo cual no implica necesariamente aumentar la duración nominal de la educación media.

Padre o madre: "Yo estoy de acuerdo que deberían aumentar un año más [...] para reforzarle a los estudiantes lo que lo que es física, química y cálculo las materias más importantes porque todas son importantes todas son importantes pero por ejemplo si alguien va a estudiar ingeniería significa que necesitamos esa materia [entonces estoy] de acuerdo en que les aumentan un año más para que el estudiante salga mejor preparado más preparado hoy, tenga más buenas herramientas para meterse en el futuro" (P10: GP-S-smp-imv).

Docente: "Yo insisto en la educación media, una propuesta de los dos años más, que no haya técnico sino que todos los colegios oficiales tengan dos años más pero reformar el pensum académico con asignaturas concertadas con la universidad" (P11: GD-S-bet-sjb).

Docente: "Yo propondría un último grado donde el estudiante desarrolle un proyecto de investigación productivo en el área que sea [...] que le gusta lenguaje, su proyecto investigativo en lenguaje y en algo que sea productivo para llegar por ejemplo a un o una forma que le gusta la sociales desarrolle un proyecto de investigación donde en esas sociales pueda hablar de geografía, pueda hablar de derecho, pueda hablar de ética, pueda hablar de lo que quiera y haga su proyecto de investigación y póngalo como en una función productiva que le gusta el deporte entonces su comité de deporte investigativo hace su club, su trabajo practico y [si] le gusta el arte haga su proyecto investigación en un arte cualquiera que sea, le gusta la ciencia entonces [lo desarrolle ahí] tiene todas las áreas" (P17: GD-Amed-ilm). 
Docente: "Si estamos hablando de inclusión no es dar dos o tres becas cierto si estamos hablando de inclusión es dar educación a todo el mundo que si estamos hablando de eso también estamos hablando bueno lo público lo público es para todo el mundo no para dos o tres pero entonces si al pelado le enseñamos algo un oficio entonces desde lo que él quiera hacer y le profundizamos ese oficio necesitamos incrementar 12, 13 o 14" (P25: GD-A-cab-ifc).

Docente: "Ahora también que haya aún más escuelas que ofrezcan así como las normales un grado o dos grados más para que salgan los estudiantes con alguna profesión, con alguna algún énfasis para que ellos también tengan oportunidad a nivel laboral" (P 3: GD-S-lpc-ilp).

Sin embargo, algunos padres de familia consideran que el tiempo de duración de la educación media es adecuado. A pesar de ello, sugieren que durante este periodo se debería profundizar en algunas áreas temáticas y asignaturas para que se facilite el ingreso a la educación superior.

Padre o madre: "Sí, si está bien [el tiempo de duración de la educación media] por ejemplo los que tienen la posibilidad de seguir estudiando yo creo que apenas es hora $[\ldots]$ O sea los que tienen la posibilidad de ir a la universidad pues muy bueno porque más ligero terminan ¿cierto? El hijo terminó de 16 y a los 23 ya estaba listo ¿cierto? O antes a los 22 salió súper ligero de la universidad” (P18: GP-Amed-ilm).

Padre o madre: "por ejemplo yo creo más bien es que los dos años son suficientes para los muchachos prepararse bien y para hay en ese transcurso de ese tiempo ver que es lo que van a hacer, yo creo que es un suficiente tiempo" (P18: GP-Amed-ilm).

Padre o madre: "Para mí personalmente me parece bien, pues sí porque salen, sobre todo con esta calidad de educación que reciben de aquí salen [...] si sobre todo con buenas bases, con buenas cimientos y para ingresar a la universidad hay muchas posibilidades" (P20: GP-A-med-ipb).

Padre o madre: "Yo creo que los dos años de educación media son [...] adecuados porque los chicos ahí más se enfatizan en esa área se perfecciona, se perfeccionan más en sociales, economía, ciencias políticas y aprenden más a profundidad lo que 
es química y física que la van a necesitar mucho y matemáticas en una carrera más adelante y ya sí creo que son adecuados" (P21: GP-A-vba-irc).

\subsection{Contenidos curriculares de la educación media}

$\mathrm{Al}$ analizar las percepciones de los actores se encuentra la idea de que los contenidos curriculares deben ser transformados. Los docentes y los padres de familia lo expresan de forma diferente, pero se pueden identificar algunas temáticas constantes:

1. Contextualización del currículo de la educación media de acuerdo con las características regionales.

2. Mayor énfasis en la práctica antes que en los contenidos teóricos, concentrándose en aprendizajes útiles para la vida laboral.

3. Intensidad horaria destinada a las asignaturas variable de acuerdo con los caracteres de la educación media (académica o técnica).

\subsubsection{Contextualización del currículo de la educación media de acuerdo con las} características regionales particulares

Algunos docentes consideran problemático el tema de la estandarización, ya que resaltan la necesidad de que los aprendizajes de los estudiantes de la educación media obedezcan a los contextos específicos de cada región.

Docente: "La parte de los derechos básicos de aprendizaje es llevar un contenido con esa parte de contextualizar, ver como los pelaos trabajan la matemática de la pesca de la coja allá porque es que las pruebas no las contextualizan yo llevo contextualizada a la región pero con la pruebas saber y las pruebas saber están diseñadas para los muchachos de la ciudad entonces tampoco la contextualizan a la región donde está el muchacho, entonces hay que trabajar eso sí pero el Ministerio tampoco contextualiza: la misma prueba que se coloca al niño en Bogotá misma prueba se la colocan a los niños rurales pueden coger del mejor colegio de Bogotá y en la misma que le colocan al niño acá, entonces tampoco está contextualizado en cierta forma" (P13: GD-S-pal-cdr).

Docente: "[...] seño si yo me pongo a mirar que todos sean universitarios eso va a ser imposible [...]; por el contexto sería un fracaso, si te digo a ti que fuera por ejemplo técnico aquí a la gente no se le ve ese ánimo, pero o sea yo te voy a decir una cosa aquí en esta zona la educación que debe imperar es como decirle a la gente, no sé ¿qué quieres tú?, ¿qué quieres ser? No yo quiero ser moto taxista 
bueno, vamos a enseñarte a ser moto taxista el mejor que aprenda educación vial que aprenda a arreglarla esa no hay otra porque yo no veo más. Ay, yo quiero ser agricultor, que es muy difícil, porque acá casi nadie posibilidad tiene, bueno entonces que sea el mejor cultivador hasta ahî” (P1: GD-S-cha-iec).

Docente: "Eso es una estandarización de la educación, como se les ocurre pensar que todo Colombia tiene las mismas capacidades no, yo no puedo pensar en la educación en [establecimiento educativo], igual al de [otro establecimiento educativo] o a [otro establecimiento educativo], uno dice pues cómo, las problemáticas sociales no son iguales y si las problemáticas sociales no son iguales, no puedo pensar en una educación igual yo no puedo dictar, yo no puedo dar mi clase la misma clase no la puedo dar exactamente en dos lugares en no funciona, no funciona" (P29: GD-A-med-imd).

\subsubsection{Mayor énfasis en la práctica que en los contenidos teóricos, concentrándose en} aprendizajes útiles para la vida laboral

También, los participantes argumentan que la educación media debería trascender los conocimientos teóricos y ofrecerles a los estudiantes la oportunidad de llevarlos a la práctica, de esta manera, ellos podrían darle sentido a sus aprendizajes y encontrarles utilidad en la vida cotidiana. En los argumentos, los participantes no plantearon propuestas muy claras o concretas de cómo lograr esta cuestión. Sin embargo, sí existe una percepción generalizada de que la educación media debería dejarles un valor agregado a los estudiantes en términos de habilidades para la vida laboral.

Docente: "Yo creo que la educación media debe ser más práctica, más de oficio, que el estudiante salga de décimo y once sabiendo un oficio que no sea un teórico, que no de pronto no se sabe qué aprendió y que se desempeñe enseguida y se le meta más academia más universidad, que en décimo y once debe, en décimo y once debe tener unos principios universitarios prácticos, que digan el alumno que sale allá del colegio tal sabe hacer esto y que venga la empresa y lo coja enseguida ¿cierto? pero de pronto los colegios saben teóricamente o sea el alumno no es práctico [...] después de que fuera más práctica me parece que era suficiente" (P11: GD-S-bet-sjb).

Docente: "Hay que hacer una reingeniería no solo del currículum (sic), todo la metodología sino de la parte de estrategia a la hora de enseñar y hay que tratar de 
enfocar a los estudiantes hacia un futuro de la mano con los temas, porque hay que mencionar esa palabra así uno no quiere de la mano con los temas hay que enseñarle al estudiante para qué le sirve eso porque ellos sí preguntan eso" (P1: GD-S-cha-iec).

Docente: "Yo llevo 40 años aquí, pues desde estudiante, y son los mismos talleres [...] con el esfuerzo y con la pertinencia de los profesores, de mis profesores que todavía hay algunos, ya otros la mayoría se han jubilado, he luchado con esto, sostener, lo poquito que nos dejó el ministerio de educación y lo poquito que se ha podido lograr, con mucho esfuerzo [...] pero si nos hace falta muchas cosas, lógico, si nosotros queremos dar un bachillerato técnico de calidad, nos falta muchas cosas, pero dentro de lo que nosotros podemos rescatar, hemos trabajado con esto, nosotros trabajamos con lo que hay; porque nosotros lo cuidamos, nosotros nos apersonamos de eso y le damos mantenimiento,[...] tenemos sentido de pertenecía y le enseñamos al muchacho que lo que tiene hay que cuidarlo, hay que dejarlo también si no, si llegan cosas nuevas hay que dejarle al que sigue, entonces ahhh... la infraestructura no es de nosotros pues ya eso lo sabemos, pero lo poquito, que tenemos con eso podemos dar el bachillerato acá" (P19: GD-Scha-iec).

\subsubsection{Intensidad horaria destinada a las asignaturas de acuerdo con las modalidades}

Algunos docentes que enseñan en el carácter técnico observan desventajas en la forma en que se distribuyen los tiempos para las asignaturas, en comparación con el carácter académico. En este caso, se debería revisar dicha distribución a la luz de lo que demanda cada carácter en la educación media. Además, se plantea que en los establecimientos públicos la ley los obliga a cumplir con un número exagerado de asignaturas. Este planteamiento suele estar acompañado de la mención a la "libertad" que tienen los establecimientos privados para fijar las asignaturas y su intensidad horaria. Al no contar con una autonomía para organizar mejor las asignaturas, los estudiantes no pueden dedicar el mismo tiempo a asignaturas que consideran primordiales como las matemáticas y ciencias básicas. En cambio, las instituciones privadas pueden distribuir sus clases entre un número menor de asignaturas, lo que favorece a los estudiantes en las pruebas de Estado según lo manifestado por los actores.

Docente: "Fíjese la diferencia que encontramos en una educación en un estudiante hecho en una institución privada y en una institución pública y podemos los 
docentes estar orientando el proceso en ambas pero en una gozamos de una situación social económica y política diferente a la otra mientras nosotros aquí debemos cumplir con 12, 15, 16 asignaturas en el grado sexto a grado once; los privados siendo privados manejen 4, 5, 6 asignaturas y no pasa absolutamente nada, ellos lo hacen y se refleja ¿dónde? en los resultados que toma el gobierno para darnos cuchillo a nosotros porque nos dicen que nosotros como educación pública tenemos falta de calidad, pero resulta que le estamos dedicando una cantidad del tiempo que compartimos con los estudiantes a otras cuestiones diferentes a eso, las privadas en la parte cognitiva le dedican más cantidad de tiempo y no tienen las mismas intensidades horarias" (P11: GD-S-bet-sjb).

Docente: "Los bachilleres académicos y si son instituciones privados con mucha más razón porque no le están dedicando tiempo a la religión, a la educación física de 30 horas, 37 horas porque ellos manejan 38 horas: 6 de química, 6 de matemáticas, 6 de física y 6 de filosofía y ahí está el pensum y ustedes van a responder mejor esto y tome y lea y tome y lea, los resultados siempre van a estar por encima de nosotros, los públicos. Entonces, no tenemos las mismas condiciones ni las mismas situaciones, entonces pues si ustedes van a presentar un trabajo para ver la educación media también deben tener en cuenta de hacer esa sugerencia de que al momento de hacer las evaluaciones se tenga en cuenta eso, las modalidades especificas porque hay modalidades específicas para las educación medias que estén prestando las diferentes instituciones" (P11: GD-Sbet-sjb).

Docente: "Yo estoy seguro de que en el informe que ustedes van a presentar, una conclusión va a ser que en las instituciones educativas de educación media técnica no hay unificación de criterios para la intensidad semanal horaria de asignaturas" (P13: GD-S-pal-cdr).

\subsection{Edad de egreso de los estudiantes}

Según los actores, la edad de egreso de la educación media oscila entre los 15 y los 18 años e incluso algunos estudiantes se gradúan a los 20 años en las zonas rurales. A pesar de que algunos actores consideran provechoso salir a temprana edad de la educación media, particularmente pensando en el ingreso a la educación superior, es mayor el número de comentarios a favor de un egreso un poco más tardío. A continuación se 
presentan algunas de las razones por las que los participantes sugieren un egreso a mayor edad:

Docente: "Estadísticamente está comprobado que esos estudiantes que salen tan jóvenes, desertan o se cambian de carrera e igualmente van a perder de uno o dos años" (P 7: GD-S-slg-tag).

Docente: "Pero sería para profundizar en algo laboral o sea que para que cumplan los 18 pero en algo laboral" (P 1: GD-S-cha-iec).

Docente: "En particular a mí no me gusta que salgan muy jovencitos, porque algunos temas de asignaturas los cerebros aún no están preparado para digerirlos y yo creo que eso es una problemática que nosotros tenemos en la educación en Colombia yo tengo experiencia en educación superior, y me encontrado con estudiantes que llegan con 15 años y han tenido problemas de adaptación. Porque a ya se encuentran con gente mayor, con gente que fuma, con gente que toma a una vida diferente a la que ellos traían de niños y esto le ha costado el semestre" (P 7: GD-S-slg-tag).

Padre o madre: "Es que digamos un muchacho de bachiller de 16 años hoy en día no consigue trabajo porque ya están exigiendo que por lo menos tengan alguna técnica y la libreta militar [...] bueno sin embargo un muchacho de 16 no trabaja sin que es muy poco lo que trabaja [...] por lo menos a mi hijo no lo recibieron en ningún trabajo por ser menor de edad [...] me parece que todavía están muy [in]maduros (sic) todavía no saben lo que quieren y saber que es una responsabilidad" (P30: GP-A-med-imd).

Docente: "El muchacho no está preparado para la educación, él sale con la expectativa de no pasé, cuando se presentan a las universidades, la angustian que sienten por ejemplo al no pasar una prueba, el cambio de universidad, es que hago, realmente que voy hacer laboralmente, primero no tiene 18 años, porque antes tiene que pedir permiso al ministerio, a los padres [...] y todas esas cuestiones, entonces miremos que ahí el pelao (sic) sale frustrado desde ese ciclo de vida, de estudio" (P29: GD-A-med-imd).

Padre o madre: "Entré a la universidad a hacer mi primera carrera a los 15 años, y ahora que estoy haciendo mi segunda carrera es totalmente diferente, yo creo que a esta juventud le falta madurar todavía mucho más antes de ingresar a una 
universidad. [Debería salir] de mayor edad en algunos colegios ya se está implementando el grado 12 por lo mismo porque es que esta juventud no generalizó, porque hay jóvenes, niños muy responsables pero estamos en un medio donde a esos muchachos hay estarlos empujando hay que estarlos llevando hay que estarlos o sea a mí no me tenían que decir que hiciera nada, uno tenía su propia responsabilidad su propia formación donde uno llegaba y sabía que tenía que seguir estudiando sabía que tenía que seguir y muchas veces a ellos hay que llevarlos, motivarlos, o sea a esta juventud le falta motivación" (P24: GP-A-vvjimv).

Docente: "Pero la mayoría de mi tierra en su regularidad salen a los diecisiete años entonces si se propone un año más yo creo que los muchachos saldrían mucho más preparados ya con más: cédula o con una posibilidad aumentar la labor a un empleo" (P23: GD-A-vvj-imv).

\section{Las relaciones que se tejen alrededor de la educación media}

Para los actores sociales es crucial que la educación media consolide unas relaciones con la familia, la educación superior y el sector productivo. Observan que las familias son fundamentales para contribuir al desarrollo de las potencialidades de los estudiantes y en el mejoramiento mismo de los establecimientos educativos. Teniendo en cuenta que los actores aseveraron que la educación media tiene el doble propósito de preparar a los estudiantes para el ingreso a la educación superior y al mercado de trabajo, las relaciones con las instituciones de educación superior y el sector productivo son de primer orden. Las instituciones de educación superior y el sector productivo contribuyen a que los estudiantes comprendan las competencias y habilidades que deben desarrollar para poder ingresar a dichos sectores y al mismo tiempo muestran caminos de desarrollo futuros. Desde esta perspectiva, la educación media requiere establecer relaciones fluidas con otros sectores de la sociedad que resultan cruciales no solo para alcanzar las funciones sociales y educativas asignadas a ellas, sino también para ayudar al tránsito de los jóvenes una vez se egresen de la educación media. Los resultados muestran que la mayoría de los docentes y algunos padres de familia entienden la importancia de que el colegio no sea un ambiente aislado de su entorno, esto no es nuevo pero no por eso se debe dejar de insistir en eso mientras no se consiga este objetivo. 


\subsection{Relación de las familias con los establecimientos educativos}

El interés de padres y familiares por el proceso educativo de los jóvenes que cursan la educación media incide significativamente en su formación, pero también en las transformaciones y mejoramiento continuo de los establecimientos educativos.

En este apartado se identificó que algunos padres asumen un rol activo en la educación de sus hijos, participando propositivamente en las actividades propuestas por los establecimientos educativos:

Docente: "La comunidad y los padres de familia pues ha habido buena simpatía, bien la ventaja de que muchos padres de familia que ahora tengo ese rol de interactuar con ellos fueron mis alumnos, estoy tratando con muchachos de 14, 13, 12 que ya son hijos de muchachos que cuando yo llegué aquí en el año 90 fueron mis primeros estudiantes entonces por eso hay buenos consejos y el ambiente a nivel de mis colegas de mis compañeros fuera de que son mis compañeros son casi mis hermanos, compadres una familia, una bonita familia, hay unos que se han ido ya buenos compañeros pero el ambiente es positivo, bueno buena compañía es importante" (P11: GD-S-bet-sjb).

Padre o madre: "Pues tenemos que tener los ojos abiertos, o sea, antes de terminar el período tenemos la responsabilidad de mirar a ver en que están fallando nuestros hijos, tenemos también la posibilidad de tenerlos controlados de mirar a ver que materias están perdiendo, y ellos pueden recuperar antes de terminar el periodo para que no quede con muchas materias que perdió. [...] también tenemos la posibilidad de mirar el horario que tiene los profesores, entonces sabemos qué hora libre tiene los profesores y podemos venir a hablar con él, por decir profesor de inglés de matemáticas, ellos tiene ciertas horas libres en la semana" (P20: GPA-med-ipb).

Los padres que se integran activamente con el establecimiento educativo logran acceder a oportunidades de formación para ellos mismos como las ofertadas en las escuelas de padres:

Padre o madre: "Bueno yo aquí estuve en una reunión y nos dieron una charla a los padres, cómo debíamos tratar a nuestros hijos que debíamos hacer que no debíamos hacer, cuáles eran nuestros deberes con ellos. Eso lo hicieron una vez aquí pero lo hicieron una sola vez. Ya entonces esa parte también ayuda pero si lo 
hicieran más seguidamente, darle como que esa charla a los papás eso ayudará mucho" (P 2: GP-S-cha-iec).

Padre o madre: "Mire lo que pasa es que aquí tenemos un cuerpo de docentes excelente yo no tengo queja de ninguno de ellos [los conozco a todos y] ellos trajeron proyecto aquí [...] se están educando padres de familia, padres que están terminando el bachillerato aquí, en esta institución los sábados, [...] primero trajeron uno que era para terminar la primaria, se era Cafam. Yo termine la primaria aquí [...] lo sábados, ahora se están preparando para terminar el bachillerato" (P 8: GP-S-slg-tag).

Padre o madre: "Aquí hacen reuniones de padres de familia también se reúne la escuela familiar [...] puede venir si quiere la pareja, hacen dinámicas, traen personas para que le enseñen a uno para que den conferencias, muy buenas ( I: ¿y ustedes asisten?, ¿todos?) sí, la mayoría [de los que estamos en el grupo focal], muy poquitos son receptivos al llamado pero la mayoría viene" (P18: GP-A-medilm).

Padre o madre: "Escuela de padres como más o menos cada dos meses, si lo citan (I: ¿A todos?)... no por grupos, suponiendo sexto y décimo y así los van juntando y así nos van, con psicólogos, con médicos, o sea una charlas" (P26: GP-A-cabifc).

Lamentablemente, por lo general, este grupo de padres que participan activamente es reducido y en varios establecimientos educativos existe la sensación de que siempre participan "los mismos":

Docente: "Muy poquita la asistencia, es más lo hacemos por grado y décimo como: hoy viene los de quinto ${ }^{2}$ y no vienen ni diez [...] a los que vienen les gusta porque damos charlas de autoestima, motivación y varias temáticas, lo que hablamos a muchos los interesa, pero no, y los que bien soy muy poquitos, normalmente los que vienen son porque son responsables con sus hijos, no los que tienen esas problemáticas complicadas, y son a esos los padres de familias que necesitamos acá, pero nunca contamos con la participación de ellos acá” (P 7: GDS-slg-tag).

${ }^{2}$ Se refiere al quinto grado de bachillerato, como también es conocido el décimo grado. 
Padre o madre: "Siempre por lo general los comunicados son por escrito pero siempre da la casualidad de que venimos los mismos siempre los mismos [...] pero si es por escrito las Asistencia aquí es minoritaria de padres de familia para que yo digo que hay algunos que van mal y los padres de familia no vienen y siempre son los mismos" (P12: GP-S-bet-sjb).

Docente: "Esa parte lo veo un poco flojo por decirlo así, con los padres de familia, ellos se convocan a la reunión y siempre llegan los mismos siempre son los mismos que uno convoca para una reunión para entregar en cosas académicos no llegan y profesor mándeme lo que fulanito saco en el informe, ahí sí es muy poco el acompañamiento por esa parte de los padres de familia, puede ser por la misma situación de sus labores, ellos son unos campesinos humildes me imagino que el tiempo que tienen es para dedicarle a su poquito de arroz" (P13: GD-S-pal-cdr).

Por otra parte, en todos los establecimientos educativos se suelen encontrar familias poco interesadas en participar en los procesos académicos y formativos de los estudiantes. Este desinterés se hace manifiesto en actitudes de poca participación y colaboración en las actividades extracurriculares, pero incluso también en reuniones obligatorias como las entregas de boletines de calificaciones.

Docente: "No hay el acompañamiento que debiera existir del padre con el estudiante, entonces uno dice [...] no están dando la importancia al proceso educativo ellos no están viendo como la educación puede transformar a esa familia como puede tender al desarrollo o progreso de esa familia si lo supieran estarían más comprometidos pero como hacérselo saber si se cita y uno dice bueno en la escuela de padres vamos a motivar a estos padres, decirle lo importante que es que estén vinculados que hay que animar a su hijo que se esfuerce que a través de la educación pueden crecer, no casi no asisten inclusive hace como dos semanas se realizó una fiesta, la fiesta de la pareja a cada estudiante se le dio una tirita para que trajera dos padres a los dos padres o la mamá y a la tía la mama o a la abuelita bueno dos adultos por estudiante no alcanzamos a tener doscientos cincuenta padres tanto así que no!, todos los pudimos reunir ahí en el patio salón aun sabiendo que íbamos a dar anchetas por salón que si iba [...] o sea, para motivar la asistencia se rifaba una ancheta por cada salón y ni así es eso [...] es la falta de compromiso y de apoyo a la labor" (P27: GD-A-med-iec). 
Docente: "El gran problema que hay acá es que muchos padres, es muy doloroso decirlo, mandan a los estudiantes a las instituciones a estudiar es para ganarse el auxilio, subsidio que manda el gobierno, eso es una debilidad y una realidad que el gobierno siga dando subsidios porque la gente se vuelve floja y no trabaja; entonces aquí han habido varios casos de familia que se molestan que lo citan que porque el niño cometió cualquier falta, los cita uno como profesor y le dice a uno en la cara ' $¿$ a eso fue a lo que usted me llamo profesor? ya tengo que ir a trabajar, ese muchachito es un problema'. Entonces no hay una relación lógica entre la relación padre-institución-hijo no lo hay precisamente porque se corta la relación cuando se trata buscar al padre para la información de cómo es el comportamiento del hijo dentro de la institución" (P13: GD-S-pal-cdr).

Padre o madre: "Mucha colaboración, porque yo he visto, y porque he venido a algunas reuniones, en donde algunos padres no se dan ni por enterados de todas las cosas del colegio ni de los hijos, yo me acuerdo la primera reunión que hicieron este año mi niño ya está en noveno y me dio tanta tristeza llegar a ese salón y ver de que los papas no vinieron a la reunión, a la primera reunión del año, no vinieron sino cuatro personas, o sea, el del colegio puede estar muy pendiente de los hijos, pero cero interés de los padres" (P20: GP-A-med-ipb).

Por último, en esta sección es necesario reconocer la influencia que tienen los padres y familiares, así como el contexto en el que vive el estudiante, en la construcción de su proyecto de vida. Se hace necesario que la familia no solo asuma un rol más activo en los procesos de formación de los estudiantes, sino que además los motive para que pueda desarrollarse como una persona integral.

Docente: "Entonces es que este problema [...] he escuchado y escucho que en décimo o en once que los pelados, que no sé qué, la mayoría han hablado de bachillerato, claro, pero es que ellos van a hacer acá lo que se les está formando, o sea cómo es un niño que ya está en 15, 16, 14 años o sea si toda su vida desde que está empezando en un preescolar está viendo es eso que vea que mi mamá no va a hacer nada, ve a que mi mamá sale embarazada, que mi mamá deja a mi papá y se va con otro, que mi papá no hace nada si no es un flojo en la casa o sea es imposible que un niño llegue a sexto ${ }^{3}$ grado" (P 1: GD-S-cha-iec).

${ }^{3}$ Se refiere al undécimo grado de educación media. 
Docente: "Sí, es muy cuestionante cuando personas que tienen hijos en preescolar afirman no poder con el hijo dentro de la escuela y cuando un alumno manifiesta que tiene pereza de estudiar tal cosa venga salgase tranquilo que por qué y ahí mismo le echan la culpa al Gobierno que porque no le podía hacer nada al hijo que el gobierno es esto pero ahí mismo y uno educa con el ejemplo entonces si los padres tendrán medida no han hecho un bachillerato o una primaria entonces no tiene como esa voz moral cierto esa autoridad moral de decir estudie por esto y esto uno mismo no sabe ni para qué” (P25: GD-A-cab-ifc).

Docente: "Bueno el aporte que hago yo tiene que ver con el hecho de que la violencia si incidió en los padres de los muchachos que están hoy aquí en la institución. Cuando hubo violencia las primeras personas que salieron de aquí del pueblo fueron las personas que tenían las posibilidades económicas para irse y quedaron acá los que no pudieron hacerlo por ese factor económico entonces, [...] aquí la pobreza se radicó a partir de ese momento y quedaron esas personas digamos que acéfalas no tenían metas, no tenían forma de decirle a los muchachos aquí hay esto, va a pasar esto, y los muchachos se vinieron levantando con esa espiritualidad pobre, los muchachos hoy en día reflejan lo que vivieron los papás de ellos, porque ese reflejo, los padres como el caso de [madre de familia] vivieron una época en la cual había otras expectativas de pronto nosotros llegamos allí en el 94 y las cosas eran diferentes a partir de ese momento fueron naciendo los muchachos que tenemos hoy acá y esos muchachos no sé si de pronto, yo creo, yo que particularmente creo que la influencia de esa violencia a pesar de que ellos no la vivieron ni la conocieron se está reflejando en ellos que son muchachos cortos en espíritu que llegan aquí a la institución llegan al bachillerato llegan a la educación media y a mí me dicen por lo menos en el caso de la química que es donde yo me desempeño en [décimo y undécimo grado], me dicen que para qué les va servir la química a ellos si ellos no tienen ninguna inclinación hacia nada y precisamente me he comunicado con algunos muchachos que fueron estudiantes de acá y me dan la razón y dicen 'profe si supiera que hoy en día estoy necesitando lo que usted nos estaba enseñando en aquella ocasión' o sea hay una falta de espiritualidad y una falta de compromiso de ellos mismos, una falta de futuro, no sé y de pronto tenemos las manos amarradas" (P 1: GD-S-cha-iec). 
Padre o madre: "Entonces decía el rector es muy triste saber que son muchachos grandes que también necesitan que los papás se interesen por ellos, y ya, los papas que hacen como son más grandes dejémoslos solos que se defiendan como puedan, que tengan tareas que ellos mismo reclamen notas, ni siquiera reclaman notas, o sea, [...] es como nosotros descargamos la responsabilidad en ellos, como ya tienen 15, 16 y 17 años, pues que se defiendan como puedan" (P20: GP-Amed-ipb).

Docente: "Pues los padres de familia valoran mucho la labor nuestra y casi que ponen en nuestras manos el futuro de sus hijos y nos dicen que sé que no es lo ideal y no se hace hágale profesora tranquila si tiene que darle la palmada hágale tranquila, todavía manejan pues ese asunto de respeto tenemos bastante apoyo de la parte moral, espiritual, de pronto no muy física en lo académica porque son padres que [no] tienen la capacidad intelectual para ayudar a sus hijos o de tiempo requieren [sic.] de muy poco tiempo para dedicarle a los chicos de pronto en ese sentido ellos se ven un poco solos o porque los padres no tienen la capacidad académica o no tienen el tiempo de pronto no lo ven muy importante por su mismo nivel académico que tienen que dedicarse para apoyar o ayudar a los niños" (P22: GD-A-vba-irc).

\subsection{Relaciones del establecimiento educativo con el sector productivo}

Las instituciones educativas establecen vínculos con empresas del sector productivo para que los estudiantes sobre todo en el carácter técnico puedan realizar prácticas profesionales que ayuden a la vinculación laboral del estudiante al egresar de la educación media:

Docente: "Puede empezar trabajando antes de salir [...] le comento ejemplos, los otros muchachos del año pasado desde noveno, se llevarse muchachos, aprendiz, miremos pues como le van, están terminado once ahora, saben que me dijo él [la persona de la empresa que los vinculó como aprendices] los cuatro que yo tuve por favor cuando termine páseme las hojas de vida que les voy a dar el ingreso, ¿por qué? por la calidad de los muchachos, porque ellos ya vienen formados, son una disciplina laboral" (P19: GD-A-med-ipb).

Docente: "Bueno yo creo que de todos los profes soy como la cuarta de la parte académica llevo pues con todo, mi experiencia está en la parte laboral, yo estuve 10 años en una empresa y lo que decían los profes, es frente a los aprendices en la 
empresa donde laboraba eran muy apetecidos y por el mismo hecho de que ellos salían de [este] colegio, y sentían con esa autoridad de decir nosotros hemos pasado por una universidad, yo sé, sé lo mismo que sabe, mi otro compañero, nosotros desde la parte laboral, los solicitamos mucho [...] en [empresa de productos lácteos], fueron 10 años y yo tenía que ver mucho con esta parte [...] de los chicos aprendices y los solicitaban mucho [de esta institución], hacíamos [...] un catálogo de piezas, que se maneja aquí debajo de los municipios o ciudades donde estaba [empresa de productos lácteos], y ellos eran los que nos colaboraban a identificar que piezas eran para que servían, finalmente para mí los aprendices fueron de mucha ayuda y siempre eran [de esta institución]" (P19: GDA-med-ipb).

Docente: "Entonces llegan a la parte de grado décimo y once y nos solicitan las empresas aprendices y nosotros tenemos aquí los convenios con las empresas que nos solicitan $[\ldots]$ es que el convenio no es que yo, yo vaya a una empresa y diga 'venga hagamos convenio’, ¡no! Si no que las empresas que necesitan aprender, las empresas llegan, necesitamos mecánicos de automotriz, necesitamos soldadores, entonces ellos vienen y los solicitan, nosotros tenemos un formato donde los muchachos vienen llenan los formatos y es ante la ley [...], nosotros tenemos la ley del aprendiz que eso salió hace mucho tiempo y nosotros nos ubicamos con la ley de los aprendices, por lo demás el formato esta, según la ley, [...] sobre la ley de aprendiz" (P19: GD-A-med-ipb).

Docente: "Es el placer con el que ellos van a sus talleres, tienen muy definido su perfil profesional y tú hacías una pregunta ahora, que en qué empresa más pueden trabajar ellos, yo escuché [empresa de productos derivados del café] son muy apetecidos en [empresa de productos cárnicos], en muchas empresas para mí ha sido bien bonito cuando ellos dicen: 'profe vengo de trabajar', no necesitan haber terminado, muchos de hecho vienen a estudiar, vienen de la empresa vienen de la industria, entonces para mí eso ha sido muy enriquecedor y voy aprendiendo con ellos, también les veo $[\ldots]$ que son buenos lectores, $[\ldots]$ entonces ya veo que, escriben mejor, les gusta redactar, Me buscan 'profe púlame en esto, en el vocabulario a nivel técnico Industrial', manejan muy bueno léxico" (P19: GD-Amed-ipb). 
Incluso, en establecimientos educativos que ofertan la educación media académica se identificaron vínculos con el sector productivo, de tal manera que los estudiantes con mejor desempeño pueden obtener oportunidades educativas financiadas por empresas ulteriormente. Resalta el caso de un establecimiento educativo que gracias a la participación de un proyecto con la National Aeronautics and Space Administration (NASA), ha logrado que sus egresados obtengan oportunidades de educación superior en el exterior:

Padre o madre: "Es con un proyecto que tienen con la NASA ellos son observadores del tiempo (I: y ¿qué criterios tienen ellos digamos para seleccionar los chicos que salen becados o conocen ustedes esos criterios que ellos tienen?) Empiezan desde sexto [...] Eso empieza antes de sexto, es un proceso que lleva la profesora [nombre de la profesora] con un grupo de estudiantes con los que quieren seguir, con los que quieren estudiar, eso es un proceso que ella lleva con ellos hasta once (I: ¿Y de ahí salen y se van para Estados Unidos?) con el conocimiento del idioma (I: ¿ellos son becados 100\%?) ¡todo, todo!” (P24: GP-A-vvj-imv).

\subsection{Relaciones del establecimiento educativo con la educación superior}

Dentro de este apartado, como en todo el documento, se encuentra un conjunto de hallazgos más bien heterogéneos. Sin embargo, se pueden identificar algunos patrones: a) Relevancia y participación del SENA en el establecimiento educativo; b) universidades con proyectos o practicantes dentro de los establecimientos educativos; c) convenios para articular la educación media con la educación superior; d) ferias educativas y espacios de promoción de las universidades a los estudiantes de undécimo grado, y; e) becas ofrecidas por universidades a egresados de algunos establecimientos educativos.

\subsubsection{Relevancia y participación del SENA en el establecimiento educativo}

El SENA es visto como referente para la formación técnica de calidad en el país, por ello, siempre que es posible, se establecen relaciones de cooperación y articulación con esta entidad.

Docente: "Realmente aquí tenemos un convenio de articulación, entre el SENA, y las 23 instituciones del departamento de sucre que son agropecuarias, los estudiantes cuando terminan el once además de su cartón de bachilleragropecuario, reciben un certificado de actitud laboral de parte del Sena [...] porque el Sena, está más articulado, esto es lo que se llama el convenio de la 
educación mediación en la educación media técnica y el SENA, entonces en grado décimo, puede ingresar al SENA eligiendo una línea agropecuaria, $[. .$.$] pero como$ no tenemos nuevas tecnologías agropecuarias que motiven al estudiante, que tengan un plan de vida que elaboren sus propias unidades productivas para que puedan continuar con este proyecto de vida, entonces, no nos estamos diferenciando con lo que ellos hacen en casa" (P 7: GD-S-slg-tag).

Docente: "Por ejemplo en el SENA el colegio tienen un convenio con el Sena, pero lo que yo le pregunto a mis estudiantes, pero a ti si te gusta estar en el campo de sembrar y ellos responden no profe a mí me gustaría estudiar mecánica pesada, cosas así [...] Entonces lo que están viendo es que esto se ve tecnificado y quieren repetir o no la misma historia. [...] Por decir algo, su papá lo hace y ven el mismo rendimiento, pues claramente no quieren repetir, pero la línea que hay acá es la del monte, la del campo, hacen esto porque le obligan pero ellos a las 12:00 a. m. del día, a las 2 o 3 de la tarde no van a coger un machete porque quieran limpiar el cultivo, entonces hay esa imposición, el estado le está ofreciendo algo, por ejemplo ellos quieren escribirse en el SENA, pero para poder hacerlo tiene que ser por medio de la tecnología y ellos no sabe hacerlo entonces pierden allí, entonces hay muchas cosas, por ejemplo si el gobierno, estos jóvenes que ya traen y viene trabajando en el SENA pues que no los metan a inscribirse por el SENA si no por la pagina porque es muy difícil para ellos" (P 7: GD-S-slg-tag).

Padre o madre: "El SENA viene da clase pa' que vallan sabiendo (I: y ¿cómo que viene a dictar clase aquí?, cuéntenme un poquito de eso)... si pa' que vayan este [colegio] como es agropecuario, entonces ellos vienen le dictan y cuando vayan para allá [a la educación superior en el SENA] les queda más fácil entrar al SENA (I: pero ¿es un convenio que tiene el Sena de venir y dictar la clase a todos?)... (responden todos: nooo solo a noveno grado, décimo y once)" (P 8: GP-S-slgtag.).

Padre o madre: "Sí, ellos tienen un convenio con el SENA, el colegio tiene convenio con el SENA [...] Del SENA mandan un profesor cada ocho días los jueves para darle clase a los de décimo y once. [Cuando egresan de la educación media,] Ellos pueden continuar, ellos salen de acá como tecnólogos agropecuarios y ellos pueden continuar con el SENA [...] dos años más y salen como licenciados, ¿ingenieros? Licenciados” (P24: GP-A-vvj-imv). 


\subsubsection{Universidades con proyectos o practicantes dentro del establecimiento educativo}

La presencia de representantes de instituciones de educación superior dentro de los establecimientos educativos es vista por los diferentes actores como deseable y un criterio de calidad y de visibilidad. Por ello los actores consideran positivo que las instituciones de educación superior tengan en cuenta su institución para participar en proyectos de diversa índole. Las ferias de ofertas educativas son el principal espacio para que los estudiantes de la educación media se acerquen y conozcan a las instituciones de educación superior, mientras que los programas de becas son para muchos la única oportunidad de acceder a una universidad.

Padre o madre: "Aquí [ha] habido convenios por ejemplo la extensión de aquí, vecino suyo, de nosotros aquí en La Guajira ((de la Universidad de la Guajira)) este es el momento de que salió de aquí no sé por qué, no en la entrada entonces aquí ha venido aquí estuvo Cecar los sábados aquí estuvo la Universidad del Magdalena también los sábados [...] si a La Guajira los sábados, la San Martín también” (P10: GP-S-smp-imv).

Docente: "También llegaron este año unas jovencitas de Cecar, trabajadoras sociales (I: de dónde) de Cecar de la universidad, están acompañando grado octavo grado noveno en un proyecto de mejoramiento de responsabilidades, de valores con los estudiantes" (P13: GD-S-pal-cdr).

\subsubsection{Convenios para articular la educación media con la educación superior}

También se logró identificar que algunos establecimientos educativos hacen convenios para articular la educación media con la educación superior, de tal manera que los estudiantes puedan cursar, durante los dos años que dura la educación media, asignaturas de la educación superior, particularmente de los programas técnicos profesionales:

Docente: "Pero entonces la educación media técnica para los muchachos empezó en décimo porque la técnica para que se haga un estudio técnico eso es [...] dos años, y es mil doscientas horas y esas mil doscientas horas se las reparten en dos años en cuatro semestres entonces empiezan en décimo y terminan en once, ahí termina su técnico laboral entonces el muchacho va a salir con dos titulaciones: su bachillerato y además el técnico laboral, acá lo está avalando Fenalco, en su brazo educativo que se llama Fenicia [...] entonces con Fenicia se tiene convenio de los comerciantes en que los van a llevar hacer prácticas en que les hacen charlas 
periódicamente los comerciantes [...] están pues en contacto con los muchachos muy en contacto, ese es el apoyo (I: ¿Y podrían conseguir trabajo en un futuro?), pues los buenos eso se les tiene dicho de Fenalco y Fenicia el director les dice, aquí se quedan los buenos, [...] la empresa va a escoger a quien al bueno al que se le ve empeño, ganas se queda en la empresa en la práctica (I: Y para que yo me pueda graduar como bachiller técnico ¿Qué asignaturas veo adicionales?), además o sea, se tiene el horario normal de 6 a 12 y la técnica es en jornada contraria los muchachos vienen de 12 a 5 de 1 a 5 tres veces a la semana [...] (I: Y ¿Qué asignaturas dan ahí por la tarde?) eh, básicamente pues obviamente pues en asistencia de mercadeo, entonces todo lo que tiene que ver con el mercadeo, eh digamos la atención al cliente, las estrategias de mercadeo, publicidad, la atención al cliente es muy importante, entonces ellos tienen su programa bien organizado, bien montado, tiene todo" (P27: GD-A-med-iec).

\subsubsection{Ferias educativas y espacios de promoción de las universidades a los estudiantes}

\section{de grado undécimo}

En algunos establecimientos educativos se hizo referencia a campañas periódicas realizadas por instituciones de educación superior para enrolar a los estudiantes en la educación superior.

Padre o madre: "[Institución de educación superior] vino hace poquito a ofrecer los programas (I: Qué programas ofrecen ellos) [institución de educación superior] tiene, ingeniería de sistemas, tiene salud ocupacional, psicología, fisioterapia, [...] derecho, contaduría, hasta el momento no recuerdo más" (P 4: GP-S-lpc-ilp).

Padre o madre: "A veces visita en casa por casa y van repartiendo unos volantes ahí [...] No la universidad, no, cursos técnicos y corporaciones" (P 6: GP-S-sfrisf).

Docente: "Desde ahora hasta noviembre, viene una invasión de institutos: [institución de educación superior], institutos que dizque forman para el trabajo, así como se ven de aquí, igual si salen de esos institutos, unos los ve en el mototax." (P11: GD-S-bet-sjb).

Docente: "Claro, [institución de educación superior], [otra institución de educación superior] aquí llegan todas las universidades también de garaje, al final 
de cada año lectivo llegan a proponer la carrera y le dejan inclusive folletos y todo pero entonces los estudiantes se pueden emocionar en el momento pero la realidad es otra la realidad es que los papás no tiene con qué matricularlos. Inclusive con viajar nada más desde aquí de [este municipio] sobre cualquier área [capital departamental] tiene que sea \$ 10.000 pesos diariamente, luego [institución de educación superior pública] que es la el sector público tiene que quedarse porque la ley es marginalidad porque no tienen con qué almorzar allá inclusive" (P13: GD-S-pal-cdr).

Padre o madre: “Acá vienen: toda la [Institución de educación superior pública] y [...] han venido varias universidades inclusive de [capital departamental] a ofrecer todos los programas académicos que tienen para los jóvenes y [...] acá les colocan tableros con toda la información sobre lo que va a salir en el SENA sobre lo que hay en [institución de educación superior pública] y les brindan toda la orientación de acá del colegio también los llevaron a [capital departamental] para que vieran los diferentes programas, también los llevaron a [municipio aledaño] que vinieron todas las universidades vinieron a [municipio aledaño] a la ciudadela educativa para presentar toda la oferta educativa, entonces también los llevaron para que miraran" (P21: GP-A-vba-irc).

\subsubsection{Becas ofrecidas por universidades a egresados de algunas instituciones educativas}

Algunas instituciones de educación superior incluso ofrecen facilidades de pago y becas para que los estudiantes de la educación media accedan a la educación superior. Tanto para padres y docentes, los estudiantes que logran acceder a estos beneficios suelen caracterizarse por ser disciplinados académicamente. También existe una idea generalizada de que deberían existir un mayor número de becas para educación superior y garantizar mayor acceso a ella.

Docente: “Ahoritica hay unos convenios que [institución de educación superior] ahí está puesto en cartelera [Institución de educación superior], [otra institución de educación superior], [otra institución de educación superior] tiene una lista de instituciones públicas y algunas privadas en donde le ofrecen a los estudiantes y tienen prioridad inclusive en el mismo Sena los estudiantes tienen prioridad cierto, de ingreso a esas universidades sobre todo los estudiantes porque han obtenido resultados altos. [...] Quiero agregar algo por lo menos este año [otra institución de educación superior que no se había mencionado antes] que es una privada que 
es donde nosotros estamos haciendo la maestría ella ofrece a los estudiantes que son egresados de aquí de la institución becas hasta del 100\% a los egresados, hay dos estudiantes que en el año 2014 [se graduaron de la educación media y] están estudiando [allí] ya están haciendo la licenciatura uno creo que en matemáticas y la otra en español, o sea que esta institución también les ofrece muchas, muchas oportunidades a la comunidad porque esos estudiantes por el hecho de haber terminado aquí tienen esas becas lógicamente hacer todo el papeleo pero igual [...] es una ventaja que nosotros tenemos con respecto a otra institución si uno la da a conocer" (P 3: GD-S-lpc-ilp).

Padre o madre: "Posibilidades, pues porque ellos son inteligentes y se ganan becas, en [Institución de educación superior] que es publica [...] por ejemplo, aquí me he dado cuenta que aquí es como unos padres como una cosa de la iglesia, hay una cosa de la iglesia no sé quiénes son que le ayudan a los muchachos por que se han ido a estudiar filosofía, profesores, y se han ido becados como con unos sacerdotes, no sé, [otra institución de educación superior], [...] y vienen de Medellín acá y los invitan y los llevan allá, hasta a Bogotá se han ido acá hay niños que se han ido hasta Bogotá de acá y, por ejemplo un primito mío que salió de acá del bachillerato lo cogió pues salió bien de las pruebas del Icfes salió con educación media beca para [una institución de educación superior en otro municipio], está estudiando derecho allá” (P18: GP-A-med-ilm).

Docente: "Pero te cuento[Institución de educación superior pública] es básicamente gratis para los estudiantes eso la gente paga 1000 pesos semestrales y tiene una cantidad de ventajas que pues de ayudas económicas además las cooperativas en el municipio también dan becas para el estudio y mantenimiento de agricultores las cooperativas financieras dan becas para los estudiantes las oportunidades de estudio" (P22: GD-A-vba-irc).

\section{Conclusiones y recomendaciones}

\subsection{Conclusiones}

Dentro de los hallazgos se encontraron similitudes entre las opiniones de docentes y padres de familia en la mayoría de los temas abordados durante los grupos focales. Aunque en algunos casos dichas opiniones podían tener algunas diferencias de acuerdo con la ubicación geográfica del establecimiento educativo (urbana o rural) o del carácter 
de la educación media (académica o técnica) e incluso del departamento de procedencia (Antioquia o Sucre), lo cierto es que la convergencia entre las expectativas y percepciones fue sustantiva. Podría argumentarse que el contexto social en el cual habitan los actores no fue tan determinante.

Las principales diferencias se dieron entre instituciones de carácter académico y técnico, particularmente en lo relacionado con las funciones sociales de la educación media. Algunos miembros de las comunidades educativas de las instituciones técnicas consideran que es necesario que los estudiantes desarrollen competencias laborales que les permitan egresar de la educación media a ejercer alguna ocupación u oficio, mientras que los pertenecientes a las instituciones de modalidad académica están más a favor de la idea de que los egresados sigan sus estudios en la educación superior. Llama la atención que esta última postura, también es compartida por un número significativo de participantes procedentes de instituciones técnicas.

Otras diferencias que merecen resaltarse tienen que ver con los contextos económicos y socioculturales particulares de los dos departamentos seleccionados. Mientras en Sucre incluso los participantes de la capital departamental y las zonas urbanas llaman la atención sobre serios problemas de desempleo, acceso a recursos básicos y dificultades en la motivación de los jóvenes estudiantes de la educación media, en Antioquia los participantes se mostraron más optimistas respecto al futuro de la educación y de sus estudiantes en general.

En cuanto a las funciones sociales y educativas, los actores coinciden en afirmar que la educación media tiene el doble propósito de preparar a los estudiantes tanto para el ingreso a la educación superior como al mercado de trabajo. Estas funciones no son percibidas de manera excluyente, sino más bien de una forma complementaria. Al concluir su proceso de formación, los estudiantes deben estar en capacidad de tanto ingresar a la educación superior como al mercado de trabajo. Los actores sociales también consideran que la educación media debe potenciar todas las capacidades que tienen en los estudiantes tanto en sus dimensiones cognitivas, sociales y políticas. Además, esgrimen que la educación media debe estar dotada de mecanismos que les permitan a los jóvenes explorar sus intereses. Esta potenciación de capacidades y exploración de intereses es vista como un precipitado fundamental para que los estudiantes puedan definir lo que será su proyecto de vida en la adultez. 
Algunos actores cuestionan la duración de 2 años que rige actualmente la educación media. Al respecto argumentan que los estudiantes no están preparados para definir su proyecto de vida como adultos o trabajadores. En contrapartida, un grupo de actores manifiesta que 2 años son suficientes para formar a los estudiantes.

Sobre los contenidos curriculares de la educación media se encontraron diversas posturas. Por un lado, aquellas que abogan por que los contenidos den prioridad tanto a los contenidos teóricos como prácticos. Esta aseveración está intrínsecamente ligada al hecho de que la educación media debe dotar a los estudiantes tanto de capacidades académicas como prácticas para que puedan afrontar después la educación superior y el mercado de trabajo. Por otra parte, algunos actores —especialmente los docentes- que claman porque los contenidos respondan a los contextos y realidades que circundan a los establecimientos educativos. Esta percepción es mucho más pronunciada en establecimientos educativos en zonas rurales en los cuales se dice que es urgente que la educación media esté dirigida a que los estudiantes perciban el campo como una opción de vida una vez concluyan la educación media.

Es indiscutible que el cumplimiento de las funciones sociales y educativas de la educación media dependen de las relaciones que esta tenga con las familias, la educación superior y el sector productivo. Las familias son percibidas por los actores como unas aliadas en el proceso educativo de los estudiantes y en el mejoramiento mismo de los establecimientos educativos. La educación superior y el sector productivo resultan de primer orden para que los estudiantes conozcan potenciales destinos educativos o laborales a los cuales pueden optar al finalizar la educación media. Igualmente son espacios que les permiten comprender las competencias y habilidades que deben tener si están interesados en ingresar a alguno de estos sectores.

\subsection{Recomendaciones}

Las recomendaciones planteadas por los actores son de diversa índole. Algunos participantes proponen que los objetivos de la educación media no solo estén enfocados en la preparación para el ingreso a la educación superior y al mercado de trabajo. La educación media debe contribuir a la construcción de un proyecto de vida con sentido. Al respecto, algunos actores plantean que la educación media cuente con un año sabático dedicado a explorar distintas opciones de vida. De igual manera, sean incluidas como 
actividades obligatorias las relacionadas con la práctica de un deporte, las artísticas y culturales que son consideradas vitales para una formación integral.

Para lograr que la educación media sea más pertinente en las zonas rurales, los actores sugieren que se revisen y actualicen los contenidos de la formación agropecuaria. Esto supone, según los actores, introducir las tecnologías de la información dentro de las estrategias de enseñanza y hacer emprendimientos de educación mediante el desarrollo de proyectos productivos que muestren a los estudiantes, además, que el campo es una opción de vida. La educación media en las zonas rurales también sería fortalecida si se aumentara la presencia de las instituciones de educación superior. Estas instituciones podrían ofrecer programas de pregrado (técnicos profesionales, tecnológicos, universitarios) pertinentes al contexto rural que se conviertan en una opción objetiva a la cual puedan acceder.

Para mejorar la articulación entre la educación media y la educación superior, algunos participantes sugirieron que las instituciones de educación superior pueden ofrecer cursos para los estudiantes de la educación media que puedan ser convalidados posteriormente cuando ingresen a la educación superior. También se sugiere dentro de esta temática eliminar trabas como el servicio militar obligatorio para quienes ingresen a la educación superior. Otras formas de articulación propuestas plantean la realización de actividades académicas conjuntas (entre la educación media y la superior) como semilleros y talleres, así como mayor presencia de proyectos de universidades dentro de los establecimientos educativos.

La articulación de la educación media con el sector productivo requiere de mayor gestión y liderazgo desde los mismos establecimientos educativos. Se requiere de espacios adecuados y equipos actualizados para brindarles a los estudiantes mejores oportunidades de aprendizaje. También, algunos participantes recomendaron una integración más activa de las empresas en las aulas, de tal manera que se aprovechen las experiencias y conocimientos adquiridos por el sector productivo en la formación de nuevo capital humano. 


\section{Referencias}

Aigneren, M. (2002). La técnica de recolección de información mediante los frupos focales. La sociología en sus escenarios.(6).

Auerbach, C. F. y Silverstein, L. B. (2003). Qualitative Data: An Introduction to Coding and Analysis. Nueva York: New York University Press.

Berger, P. y Luckmann, T. (2005). La construcción social de la realidad. Buenos Aires: Amorrortu.

Canales, M. (2006). El grupo de discusión y el grupo focal. En M. Canales (ed.), Metodología de investigación social (pp. 265-287). Santiago de Chile: LOM.

Congreso de la República de Colombia (1994). Ley 115 de 1994. Por la cual se expide la ley general de educación. Bogotá: Congreso de la República de Colombia Recuperado de http://www.mineducacion.gov.co/1621/articles85906_archivo_pdf.pdf.

DeCuir-Gunby, J. T., Marshall, P. L. y McCulloch, A. W. (2010). Developing and Using a Codebook for the Analysis of Interview Data: An Example from a Professional Development Research Project. Field Methods, 23(2), 136-155. DOI: $10.1177 / 1525822 \times 10388468$.

Farías, L. y Montero, M. (2005). De la transcripción y otros aspectos artesanales de la investigación cualitativa. International Journal of Qualitative Methods, 4(1). http://www.ualberta.ca/ iiqm/backissues/4_1/pdf/fariasmontero.pdf

Fernández, L. (2006). ¿Cómo analizar los datos cualitativos? Butlletí la Recerca(6), 1-13.

García Viedma, M. R. (2011). Percepción, atención y memoria. Departamento de Psicología. Universidad de Jaen. Recuperado de http://www4.ujaen.es/ mrgarcia/Tema1PAM.pdf

Giddens, A. (1995). La constitución de la sociedad: bases para la teoría de la estructuración. Buenos Aires: Amorrortu.

Glaser, B. G. y Strauss, A. L. (1967). The Discovery of Grounded Theory; Strategies for Qualitative Research. Chicago: Aldine Pub. Co.

Hesse-Biber, S. N. y Leavy, P. (2006). The Practice of Qualitative Research. Thousand Oaks: SAGE Publications. 
Jefferson, G. (2004). Glossary of Transcript Symbols with an Introduction. En G. H. Lerner (ed.), Conversation Analysis: Studies from the First Generation (pp. 1323). Filadelfia: John Benjamins.

Korman, H. (1986). The Focus Group Sensign. Nueva York: Department. of Sociology, SUNY at Stony Brook.

Krippendorff, K. (1990). Metodología de análisis de contenido. Teoría y práctica. Barcelona: Paidós.

MacQueen, K. M., McLellan, E., Kay, K. y Milstein, B. (1998). Codebook Development for Team-Based Qualitative Analysis. Field Methods, 10(2), 31-36. DOI: $10.1177 / 1525822 \times 980100020301$.

Martínez Miguélez, M. (2004). Los grupos focales de discusión como método de investigación. Heterotopia, 10(26), 59-72.

Mühr, T. (2011). atlas.ti 6 (version 6.2.28). Berlín: Scientific Software Development $\mathrm{GmbH}$. Recuperado de http://www.atlasti.com/.

Strauss, A. L. y Corbin, J. M. (2002). Bases de la investigación cualitativa. Técnicas y procedimientos para desarrollar la teoría fundamentada. Medellín: Editorial Universidad de Antioquia.

Vargas Melgarejo, L. M. (1994). Sobre el concepto de percepción. [Último acceso: 10 de noviembre del 2015]. Alteridades, 4(8), 47-53.

Weber, M. (1996). Economía y sociedad. México D. F.: Fondo de Cultura Económica. 


\section{1] 1 los Andes}

Escuela de Gobierno

Alberto Lleras Camargo

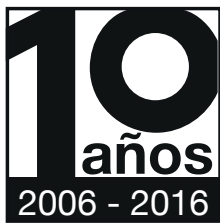

\section{PROGRAMAS ACADÉMICOS}

\section{egob.uniandes.edu.co}

\section{- Pregrado en}

\section{Gobierno y Asuntos Públicos}

Preparar líderes para transformar lo público

- Título otorgado: Profesional en Gobierno y Asuntos Públicos

(II) SNIES: 102920. Registro calificado: resolución No. 16710 del 28 de noviembre de 2013, por 7 años

-10 Duración: 4 años (135 créditos académicos, distribuidos en ocho semestres)

( Modalidad: presencial en Bogotá

\section{Maestría en Políticas Públicas}

Herramientas para mejorar el diseño, la implementación y la evaluación de las políticas públicas

Título otorgado: Magíster en Políticas Públicas

III SNIES: 90798. Registro calificado: resolución No. 2056 del 17 de febrero de 2015, por 7 años

- Duración: 2 años (42 créditos académicos, distribuidos en cuatro semestres)

- Modalidad: presencial en Bogotá

\section{Maestría en}

\section{Salud Pública}

Evidencia y enfoque global que generan cambios en la salud y en la calidad de vida de la población

- Título otorgado: Magíster en Salud Pública

III SNIES: 91281. Registro calificado: resolución No. 3308 del 25 de abril de 2011, por 7 años

- Duración: 2 años (44 créditos académicos, distribuidos en cuatro semestres)

Modalidad: presencial en Bogotá

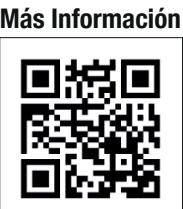

Teléfono: 3394949 ext. 2073 


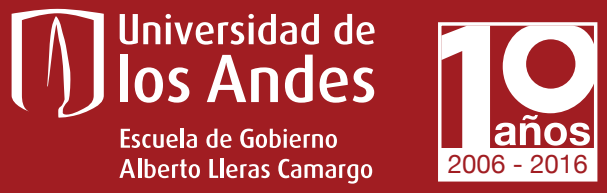

Documentos de trabajo EGOB es una publicación periódica de la Escuela de Gobierno Alberto Lleras Camargo de la Universidad de los Andes, que tiene como objetivo la difusión de investigaciones en curso relacionadas con asuntos públicos de diversa índole. Los trabajos que se incluyen en la serie se caracterizan por su interdisciplinariedad y la rigurosidad de su análisis, y pretenden fortalecer el diálogo entre la comunidad académica y los sectores encargados del diseño, la aplicación y la formulación de políticas públicas.

\author{
egob.uniandes.edu.co \\ (f fb.com/EGOBuniandes 9 @EGOBUniandes
}

